\title{
Contornos y confines del universo iconográfico precalchaquí del valle de Santa María
}

María Cristina Scattolin ${ }^{1}$

\section{RESUMEN}

Este trabajo ofrece una caracterización de la cerámica presantamariana procedente del valle de Santa María, Catamarca, Argentina. Se examinan más de 300 vasijas cerámicas de antiguas colecciones. Durante el primer milenio $D C$, los atributos "simetría dorsoventral", "vasija efigie", "cuello vertedor u oblicuo" y varios otros, fueron de uso común y reflejan una tendencia corriente, un hábito, en la confección de vasijas finas. El análisis busca contribuir y ajustar los modelos cronológico y cultural, y de legitimación simbólica para el área central del Noroeste Argentino. Los resultados de las observaciones confirman que los restos materiales atribuidos al estilo Aguada están escasamente representados en el valle de Santa María y no avalan la existencia de efectos integrativos originarios de los valles de Ambato o Hualfín. Por el contrario, las poblaciones del valle de Santa María consumieron vasijas cuyos modos de confección fueron compartidos con las Selvas Occidentales del sur, el valle de Tafí, la cuenca de Tapia-Trancas, el valle del Cajón y el sur del valle Calchaquí.

Palabras claves: alfarería - estilo - Noroeste Argentino - iconografía.

\section{ABSTRACT}

This article offers a characterisation of pre-Santamariana ceramics from Santa María Valley, Catamarca, Argentina. More than 300 ceramic vessels from old collections are examined. During the first millennium $A D$, the attributes "dorsal-ventral symmetry", "effigy vessel", "oblique neck", and several others, were currently used and reflect a common trend, a habit, in shaping fine vessels. The analysis seeks to contribute and to adjust cultural chronological and symbolic legitimation models for the central area of Northwest Argentina. The results confirm that the material remains attributed to Aguada style are barely represented in Santa María Valley, and integrative effects originated from Ambato or Hualfin Valley do not occur. On the contrary, the populations of Santa María Valley consumed vessels whose making techniques and design ways were shared with the Southern Selvas Occidentales, Tafí Valley, Tapia-Trancas Basin, Cajón Valley, and Southern Calchaquí Valley.

Key words: pottery - style - Northwestern Argentina - iconography.

Recibido: octubre 2005. Aceptado: enero 2006.

1 Museo Etnográfico Universidad de Buenos Aires, Moreno 350, 1091 Buenos Aires, ARGENTINA. Email: cris@ netverk.com.ar

\section{Introducción}

Las investigaciones de Liberani y Hernández (1850 [1877]) en el valle de Santa María o Yocavil (Figura 1), se recuerdan como el trabajo precursor de la arqueología en la historia de la disciplina en Argentina. Del conjunto de objetos obtenidos entonces, las piezas cerámicas que hoy sabemos que corresponden al primer milenio DC eran sólo dos (Figura 2a y b).

Las vasijas son de "barro negro" y no tienen contorno circular -no generan "sólidos de revolución"- sino formas de simetría dorsoventral. ${ }^{2}$ Además, una de ellas es una vasija cuyo volumen, patas y cola le confiere rasgos zoomorfos, en tanto su cuello se inserta en posición oblicua o descentrada. Hoy creo que estas formas, o más específicamente los atributos "simetría dorsoventral", "vasija efigie" y "cuello vertedor u oblicuo", fueron bastante comunes en el valle, es decir, este testimonio precoz refleja de manera cabal lo que habría sido una tendencia corriente en la confección de vasijas "finas" durante el primer milenio DC. En este trabajo trataré de sostener esta idea ofreciendo una caracterización de la cerámica presantamariana procedente de varias colecciones.

Que el primer trabajo de arqueología argentina ya informara sobre lo que más tarde se conocería como Período Formativo (600 AC-900 DC) parecía augurar que dicha información crecería rápidamente $\mathrm{y}$, sin embargo, este hecho fue de inmediato relegado al punto que la alfarería formativa de Yocavil es paradójicamente una de las menos conocidas del Noroeste Argentino (en adelante N.O.A.). ${ }^{3}$ En efecto,

2 Sensu Wolf y Kuhn (1977 [1952]), quienes deslindan las diferencias entre este término y la denominación más difundida de "simetría bilateral": ambas clases tienen dos laterales reflejos, pero los cuerpos dorsoventrales tienen un frente y un dorso diferentes; en los cuerpos de simetría bilateral no se distingue un frente y un dorso.

3 En la arqueología del N.O.A. el Período Formativo es la época de las comunidades aldeanas de base agraria y pastoril, y 


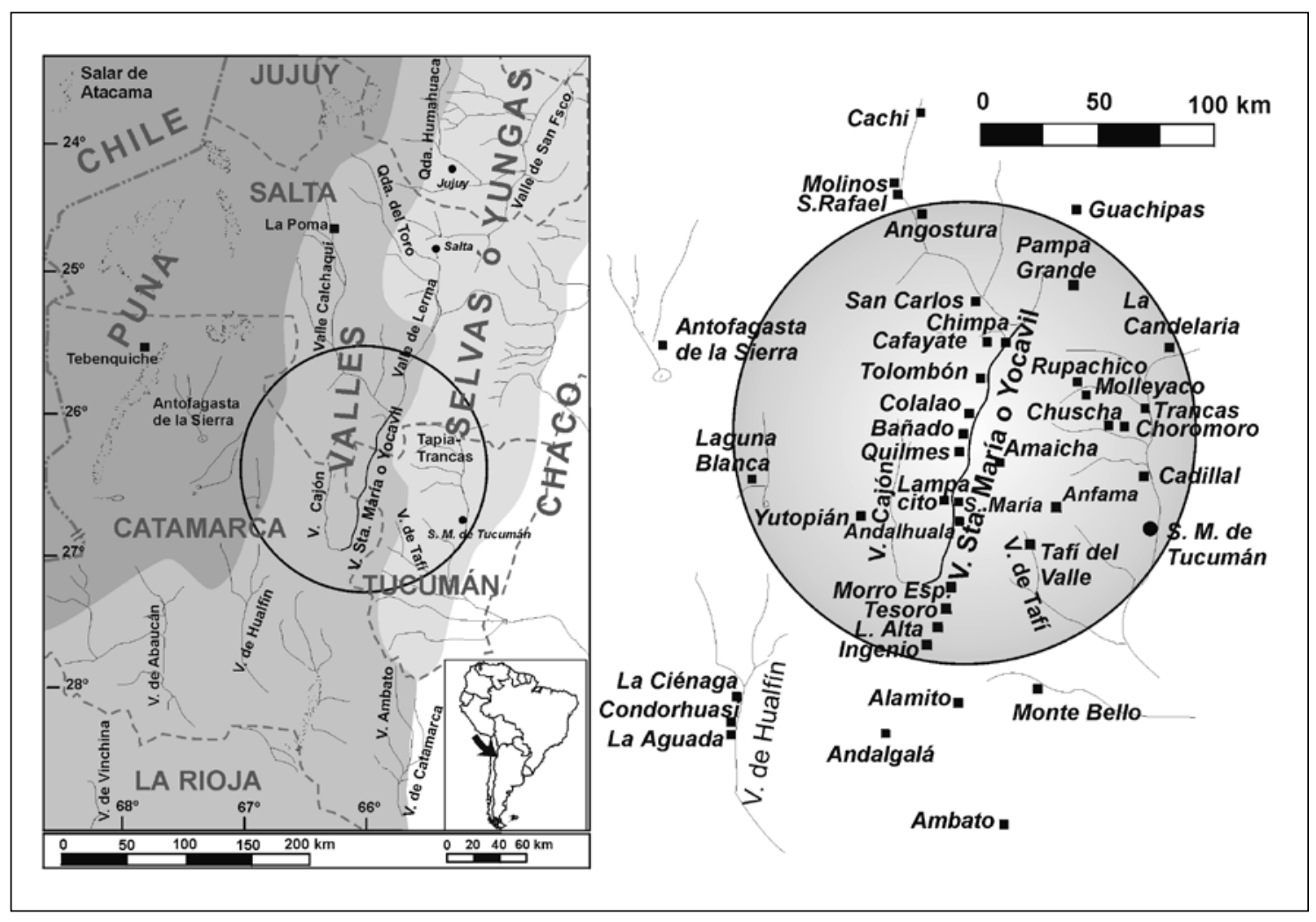

Figura 1. El valle de Santa María o Yocavil y alrededores.

hasta el día de hoy no ha habido estudios estilísticos que enfoquen de conjunto dicha alfarería. La imagen que se tiene de sus estilos cerámicos no es la de

en su transcurso se habrían desarrollado las desigualdades jerárquicas. Hay cronologías detalladas que subdividen el período, pero aquí lo tomo provisoriamente en un sentido amplio (sensu Núñez Regueiro 1974), el cual abarca las ocupaciones o componentes arqueológicos agroalfareros anteriores al Período Tardío o de los Desarrollos Regionales (de los poblados aglomerados y jefaturas establecidas y luego confederadas contra los españoles, como los grupos calchaquíes) cuyo comienzo se postula hacia "fines del siglo IX" y que presentan cerámica de estilo santamariano (Tarragó et al. 1997). En el otro extremo, el fechado más antiguo para un contexto presumiblemente formativo en el valle Yocavil podría ser de unos 500 AC (Muñoz y Stenborg 1999: 200). Para situar al lector en el ámbito más extenso del Area Andina, hay que recordar que esta trayectoria temporal es coetánea del Formativo, el Intermedio Temprano y el Horizonte Medio del Area Centro Sur Andina, términos que -por una peculiar tradición nacional-en Argentina no se utilizan. Una parte de esa trayectoria fue denominada por A. R. González, Período Temprano (600 AC-650 DC), y otra parte como Período Medio (650-850 DC), que reconoce como jalón la ocurrencia de materiales atribuidos a la "Cultura Aguada" (González 1963, 1964). estos dos primeros recipientes bastante olvidados, sino una que se ha moldeado más bien en relación a lo que se sabía de otros lugares, particularmente lo que conocemos como estilos Ciénaga y Aguada (González 1963).

Esta opacidad del registro arqueológico presantamariano se debió a una serie de factores: el gran saqueo en el área, la falta de contexto de asociación para las piezas, la expatriación de grandes colecciones hacia el extranjero que provocó una escasez de material de referencia ilustrado para comparar los fragmentos de excavación con piezas enteras, la discontinuidad en los estudios, y tampoco hubo ningún fechado radiocarbónico destinado a datar materiales pretardíos hasta casi el año 2000 (ver Scattolin 2000, $2004 \mathrm{Ms}$ ).

Así, la necesidad de superar la indeterminación de ese lapso tuvo como consecuencia una tendencia a modelarlo por referencia a elementos ya definidos con anterioridad fuera de Santa María, básicamente con las áreas más al sur, como Hualfín-Alamito, donde la mayoría de los nombres de tipos cerámicos 
y culturas formativas del área de los valles, fueron establecidos por primera vez. Ello puede apreciarse con claridad en el cuadro cronológico propuesto por A. R. González (1963: Fig. 14) y ampliamente difundido dentro y fuera de Argentina. En pocas palabras, se sobreentiende que, antes de $1000 \mathrm{DC}$, el valle de Santa María estuvo sucesivamente ocupado por las "culturas Condorhuasi, Ciénaga y Aguada", representadas por sus estilos homónimos (González 1963). Y se tiende a suponer que los cambios en la cultura material del valle son consecuencia de los mismos procesos ocurridos fuera de él. Pero esta transferencia del modelo cultural y cronológico de Hualfín no hay que darla por supuesta, hay que investigarla. ${ }^{4}$ Por eso desde hace unos años iniciamos el registro y estudio de las antiguas colecciones de artefactos. Su examen y, sobre todo, el peculiar universo iconográfico y las formas que exhiben también permiten plantear algunas consideraciones acerca de la legitimación simbólica a través de representaciones entre las poblaciones del primer milenio DC.

Como indica la Tabla 1, decenas de miles de objetos fueron destinadas a los museos, y aunque la mayoría de ellos no tienen contexto, de todas maneras, guardan una gran potencialidad para desarrollar nuevos estudios. En este trabajo me referiré solamente a la sección presantamariana de tales colecciones. Las determinaciones de una vasija como precalchaquí o presantamariana, formativa o pretardía -en tanto términos estimativos y que aquí uso como sinónimos- se basaron en atributos estilísticos, de forma, manufactura y decoración, ya que casi la totalidad carece de datos de asociación, y sólo retienen la localidad de procedencia. Si bien esta

\footnotetext{
4 En la historia de la arqueología del N.O.A. la secuencia cultural de Hualfín introdujo una ruptura con el modo de pensamiento previo sin profundidad histórica (González 1998). Sin embargo, con el tiempo, y por razones ligadas a la vulgarización, la difusión y la enseñanza escolar rutinaria, se engendró un efecto de cristalización y reiteración rutinizada del conocimiento que no es inherente al pensamiento rupturista originario y que condujo a considerar que tal secuencia era presuntamente aplicable a todo el N.O.A. Además, en el marco de "la circulación internacional de ideas" esta reproducción acrítica del modelo cronológico cultural prevaleciente probablemente sea mayor fuera de Argentina, debido a los "malentendidos estructurales" que ocurren "entre el campo de producción y el campo de recepción" y a que "la transferencia [de ideas] de un campo nacional a otro se hace a través de una serie de operaciones sociales" (Bourdieu 1990).
}

aproximación es imperfecta, no hay por ahora otra manera de establecer distinciones temporales, aunque se lo está intentando en forma paralela, mediante excavaciones y dataciones (Scattolin $2004 \mathrm{Ms}$ ). Empero, hasta que no haya más sitios excavados y fechados en número significativo que permitan una mejor resolución temporal para proponer un modelo cronológico detallado, la alternativa es quedarnos paralizados. Por eso tomaré el riesgo y espero se me permita hablar de este primer milenio DC laxamente, aunque reconozco que dentro de ese lapso deben poder distinguirse diferencias de significación temporal entre los objetos, que al momento estamos tratando de dilucidar (Scattolin $2004 \mathrm{Ms})$.

También hay que subrayar que la mayoría de las piezas cerámicas de las colecciones que trataremos aquí, lo más probable es que no procedan de basureros, habitaciones y depósitos domésticos, es decir, aquellas unidades que comúnmente se busca investigar en la actualidad, sino que, en su mayoría, es más seguro que provengan de depósitos especiales o tumbas, la unidad de extracción privilegiada por coleccionistas para obtener objetos enteros y "bellos", que es lo que les interesaba adquirir (Pérez de Micou 1998). Ello queda de manifiesto en la cantidad casi nula de recipientes ordinarios, de cocción y almacenamiento de alimentos que se presentan en estas colecciones, a diferencia de los conjuntos obtenidos en sitios habitacionales, donde la presencia de alfarería rota y de uso cotidiano es lo común.

De manera que cuando hablemos de estas vasijas no estaremos aludiendo al conjunto completo de los enseres domésticos de que disponían en el pasado, sino a un subconjunto de tales vasijas, que grosso modo podemos denominar como "finas", y que, aparte de sus fines estrictamente utilitarios como contenedores, mayormente cuencos y jarras, habrían sido empleadas en contextos de representación, de despliegue o de usos especiales, no cotidianos o discontinuos $-y$ quizás en ellos se habrían activado sus funciones y significaciones, no manifestadas por completo en el uso instrumental- como por ejemplo, cortejos, ceremonias de entierro y ajuar funerario; servicio de bebidas y alimentos en prácticas del culto, ritos votivos, liturgia, asambleas, celebraciones y procesiones; retención de posesiones apreciadas en escondrijos; conservación, transporte y servicio de pociones, brebajes, medicinas, entre otros. Incluso, el tamaño pequeño de algunas de estas vasijas y sus particulares siluetas les restan 


\begin{tabular}{|c|c|c|c|}
\hline $\begin{array}{l}\text { Colecciones del valle de Santa María } \\
\text { y alrededores }\end{array}$ & $\begin{array}{l}\mathrm{N}^{\circ} \text { de piezas } \\
\text { mencionadas }\end{array}$ & Referencias & $\begin{array}{c}\text { Vasijas } \\
\text { formativas } \\
\text { estudiadas }\end{array}$ \\
\hline Zavaleta, Chicago $^{\text {a }}$ & 4500 & Archivos Field Museum N. H. & $88^{\mathrm{f}}$ \\
\hline Zavaleta, Berlín a & 4504 & González 1983, Muñoz 2002 Ms. & \\
\hline Zavaleta, Buenos Aires $^{\text {a }}$ & $11590^{\mathrm{d}}$ & Zavaleta 1906 & 8 \\
\hline Schreiter, Gotemburgo & 400 & Stenborg y Muñoz 1999 & $21^{\mathrm{f}}$ \\
\hline Schreiter, Berlín & 173 & González 1983, Muñoz 2002 Ms. & \\
\hline Schreiter, Buenos Aires ${ }^{b}$ & 800 & Tarragó 1999 & 4 \\
\hline Schreiter, P Posse, Peirano, Tucumán & 450 & Archiv Inst. de Arqueología & $38^{\mathrm{f}}$ \\
\hline Schreiter, Viena ${ }^{c}$ & $1900 ?$ & Becker Donner 1951-52 & \\
\hline Schreiter, Leipzig & $?$ & Stenborg y Muñoz 1999 & \\
\hline Methfessel, La Plata & 1400 & Moreno 1890-91 & \\
\hline Uhle, Berlín ${ }^{\mathrm{c}}$ & 522 & Muñoz 2002 Ms. & \\
\hline Bruch, Weiser, Ten Kate, La Plata & $?$ & Archivos Museo de La Plata & $36^{\mathrm{f}}$ \\
\hline La Vaulx, Crequi-Momfort, Paris & 110 & Archivos Musee de l'Homme & \\
\hline Von Tschudi, Leipzig & $?$ & Von Tschudi 1866-69 & \\
\hline Salvatierra, Buenos Aires & 638 & Catálogos Museo Etnográfico & 17 \\
\hline Breyer, Buenos Aires & 400 & Catálogos Museo Etnográfico & 30 \\
\hline Bravo, Cafayate & $?$ & Carrara et al. $1961 \mathrm{Ms.}$ & 27 \\
\hline Museo de Quilmes & $?$ & Pelissero y Difrieri 1981 & 11 \\
\hline Vázquez, Santa María & $80^{\mathrm{e}}$ & Museo Eric Boman & \\
\hline Univ. de Rosario (ex Litoral) & $?$ & Archivos Esc. de Antropología & $5^{f}$ \\
\hline Aparicio, Buenos Aires & 203 & Catálogos Museo Etnográfico & 20 \\
\hline \multirow[t]{2}{*}{ Liberani } & 2 & Liberani y Hernández 1950 [1877] & 2 \\
\hline & $\approx 28000$ & & 307 \\
\hline
\end{tabular}

Tabla 1. Cantidades de piezas referidas en diversos artículos, documentos y archivos de colecciones del valle de Yocavil y alrededores. ${ }^{a}$ En menor cantidad incluye también materiales de Tafí del Valle. ${ }^{b}$ Incluye también materiales del norte de Tucumán y La Candelaria. ${ }^{\mathrm{c}}$ Incluye también materiales de otros valles. ${ }^{\mathrm{d}}$ De las cuales unas 6200 son puntas de flecha talladas. ${ }^{\mathrm{e}}$ Sólo piezas de cerámica exclusivamente presantamarianas. Hay además objetos de oro, plata y piedra. ${ }^{\mathrm{f}}$ Este número representa virtualmente el total de los recipientes formativos existentes en la colección referida, mediante su revisión exhaustiva. El resto de las colecciones todavía no se ha examinado íntegramente.

aptitud o limitan la capacidad de desempeñar una amplia gama de funciones prácticas. En realidad, son objetos bastante adecuados para estudiar las representaciones simbólicas.

Las vasijas han sido registradas de diversas formas: fotos, registros de catálogo, dibujos e, incluso, en la mayoría de los casos, ciertas dimensiones y otros rasgos de forma, terminación de superficie y decoración y algunas propiedades macroscópicas de pasta, cuando fue posible, sobre todo, en algunas piezas con fracturas. Se han reunido hasta ahora varios cientos de diapositivas, otras tantas fichas de registro, varias bases de datos sobre colecciones individuales, catálogos de diversos museos y dibujos. Pero la compilación de evidencias no ha cesado y se mantiene como tarea continua. Cinco de esas colecciones han sido revisadas de manera completa y el resto sólo parcialmente.
Para esta primera presentación hemos examinado los atributos formales y estilísticos de 307 vasijas procedentes de unas 20 localidades de Yocavil (Gráfico 1), analizando las siguientes variables: color, tratamiento decorativo, motivos decorativos, contorno de la sección horizontal, tipo de cuello y empleo de la representación en efigie.

\section{Caracterización estilística}

Del total de la muestra de recipientes pretardíos de Yocavil $(\mathrm{n}=307)$, el $78 \%(\mathrm{n}=236)$ son decorados y el 22\% $(n=71)$ son no decorados. Unas 185 piezas son grises o gris-negras y el resto se reparten entre beige $(n=41)$, rojo $(n=28)$, gris-pardo $(n=24)$, negro $(n=14)$, pardo $(n=10)$, rojo-marrón $(n=4)$ y rojonegro $(n=1)$. El $40 \%$ de las piezas $(n=126)$ están decoradas con incisiones no figurativas que trataré aquí muy brevemente. 


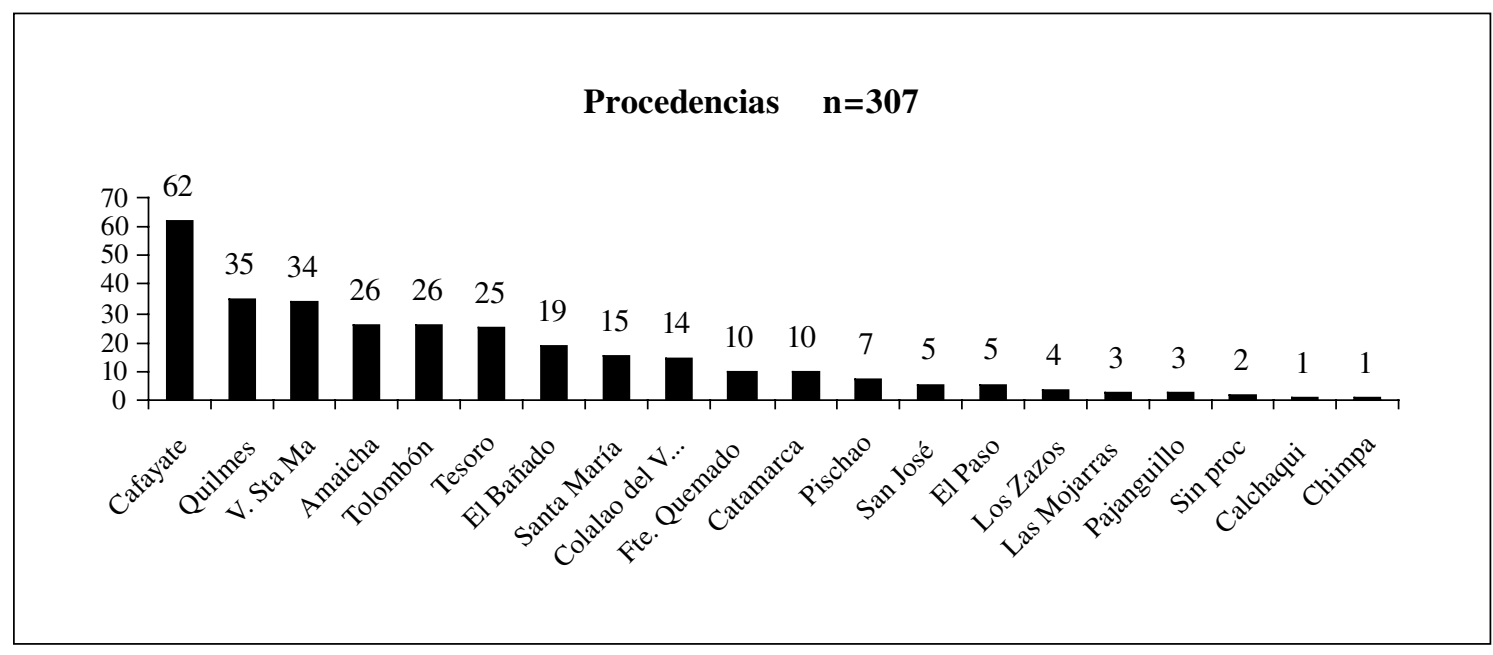

Gráfico 1. Procedencia de las piezas.

Pero lo más notable es que la cuarta parte de las vasijas $(n=79 ; 26 \%)$ comprende vasijas de tipo efigie, o sea, son recipientes en cuya forma está involucrada la figuración del personaje o motivo representado. Es decir, son vasijas prosopomorfas. El tratamiento decorativo incluye como técnicas básicas el modelado y adhesión de tiras al pastillaje y la incisión.

Las representaciones más comunes son las de seres humanos y aves. En efecto, la mitad de los vasos efigie tienen características antropomorfas $(n=40$, incluyendo los zooantropomorfos), y cinco ejemplares pueden ser identificados como femeninos por sus caracteres sexuales secundarios, pero ninguno se ha identificado como masculino. En una gran proporción hay ornitomorfos y, en menor cantidad, otras clases de zoomorfos (varios zoomorfos indeterminables, quirquinchos, dos felinos, un roedor, un batracio, entre otros; ver Gráfico 2).

Una pieza representa el tema de "la mujer que carga un cántaro", confeccionada en una cerámica gris semipulida, con rostro y piernas modelados y la vulva muy notable (Figura 2). Un segundo ejemplar femenino - presenta un orificio entre las piernas y nalgas abultadas- es más bien una figura hueca con rasgos al pastillaje e incisiones puntuadas. Otro ejemplo es la vasija que fuera prototipo de la descripción del estilo Candelaria (González 1977: 141). Hay también una pieza de Tolombón con vulva marcada y piernas voluminosas, aunque en un estilo diferente. Una quinta vasija femenina ha sido reproducida por González (1977: Fig. 70).
El resto de los ejemplares antropomorfos mantiene las características de modelados e incisiones decorativas y aplicaciones al pastillaje para representar los rasgos humanos (Figuras 2 y 3 ). Generalmente, el rostro se presenta en la porción del cuello de los recipientes. Hay personajes también con brazos en arco sobre el pecho (como en las mujeres vasijas), portando algo entre sus manos o sencillamente con la sola representación de un rostro. A veces el rostro sólo ocupa toda la vasija $(n=10)$.

Gombrich (1999 [1979]) denomina genéricamente a esta clase de piezas "recipientes animados" y considera que de manera universal cumplen funciones apotropaicas o de protección, rescatando la faceta práctica que cumplirían también las representaciones simbólicas. En sus estudios de psicología de las artes nos dice que hay hábitos perceptivos muy profundamente arraigados y que:

“... tenga o no este hábito un componente innato, es notorio que tendemos en particular a proyectar rostros en cualquier configuración que permita remotamente esta transformación. La tendencia puede contribuir a justificar ciertos motivos decorativos que deben haber surgido independientemente en muchos lugares del globo. La forma abultada del jarrón, destinado a contener un líquido, ha sido dotada a menudo de ojos y otros rasgos faciales para asimilarse a una cabeza o a un ave, o adquirir la semejanza de una figura completa y majestuosa... comprobaremos que estos y otros hábitos similares de 'animación' se ven reforzados con frecuencia por la creencia en la eficacia de los ojos, patas o garras como protección contra el mal" (Gombrich 1999 [1979]: 171). 


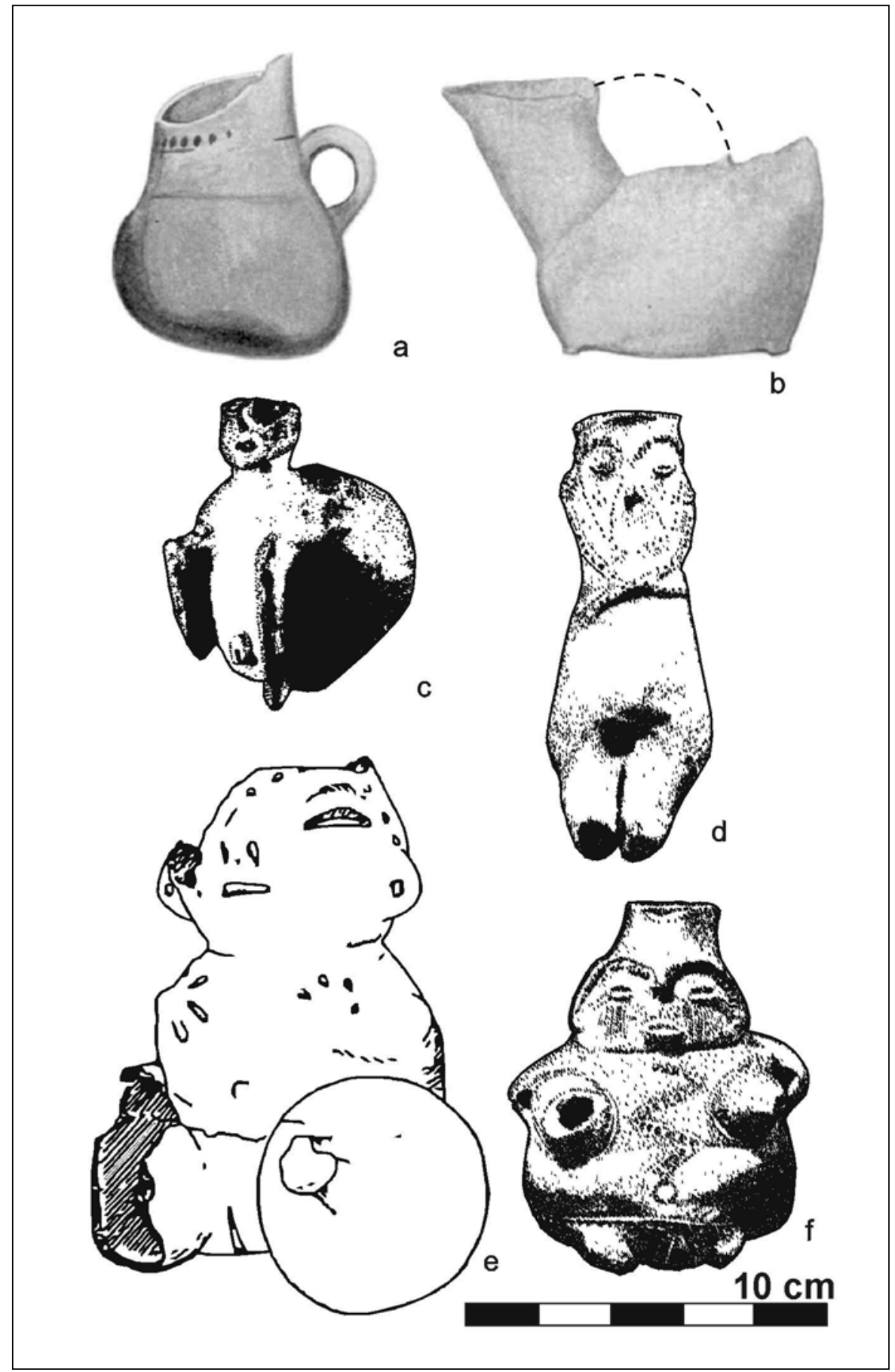

Figura 2. a y b) Respectivamente de Andalhuala y Quilmes en el valle de Santa María (tomado de Liberani y Hernández 1950 [1877]); c) Mujer portando un cántaro, gris pulido, Quilmes ( $\mathrm{n}^{\circ} 100754$, Col. Zavaleta, Chicago); d) Mujer vasija, beige pulido, Cafayate ( $\mathrm{n}^{\circ} 100614$, Col. Zavaleta, Chicago); e) Mujer-vasija, Tolombón (Museo Etnográfico); f) Mujer-vasija, marrón pulido, Santa María (tomado de González 1977). 


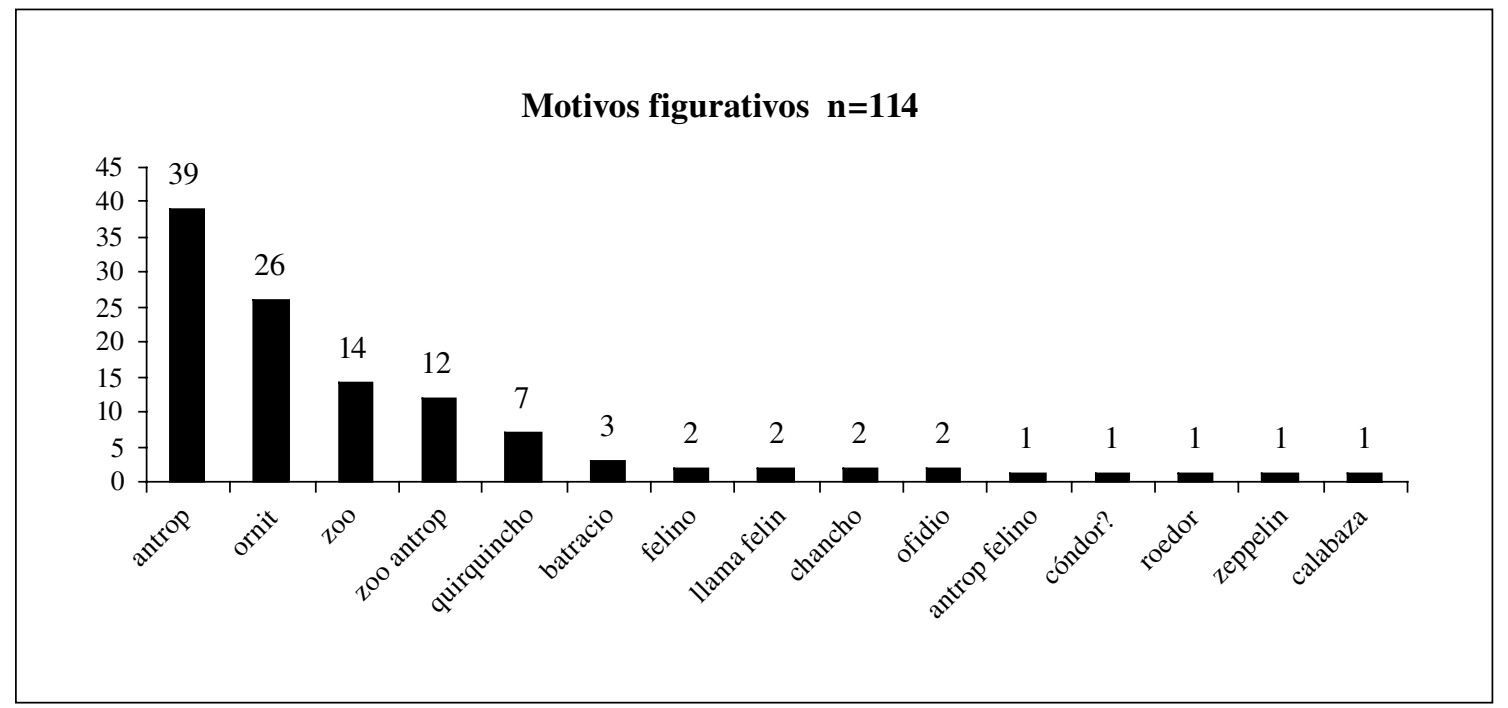

Gráfico 2. Motivos figurativos.

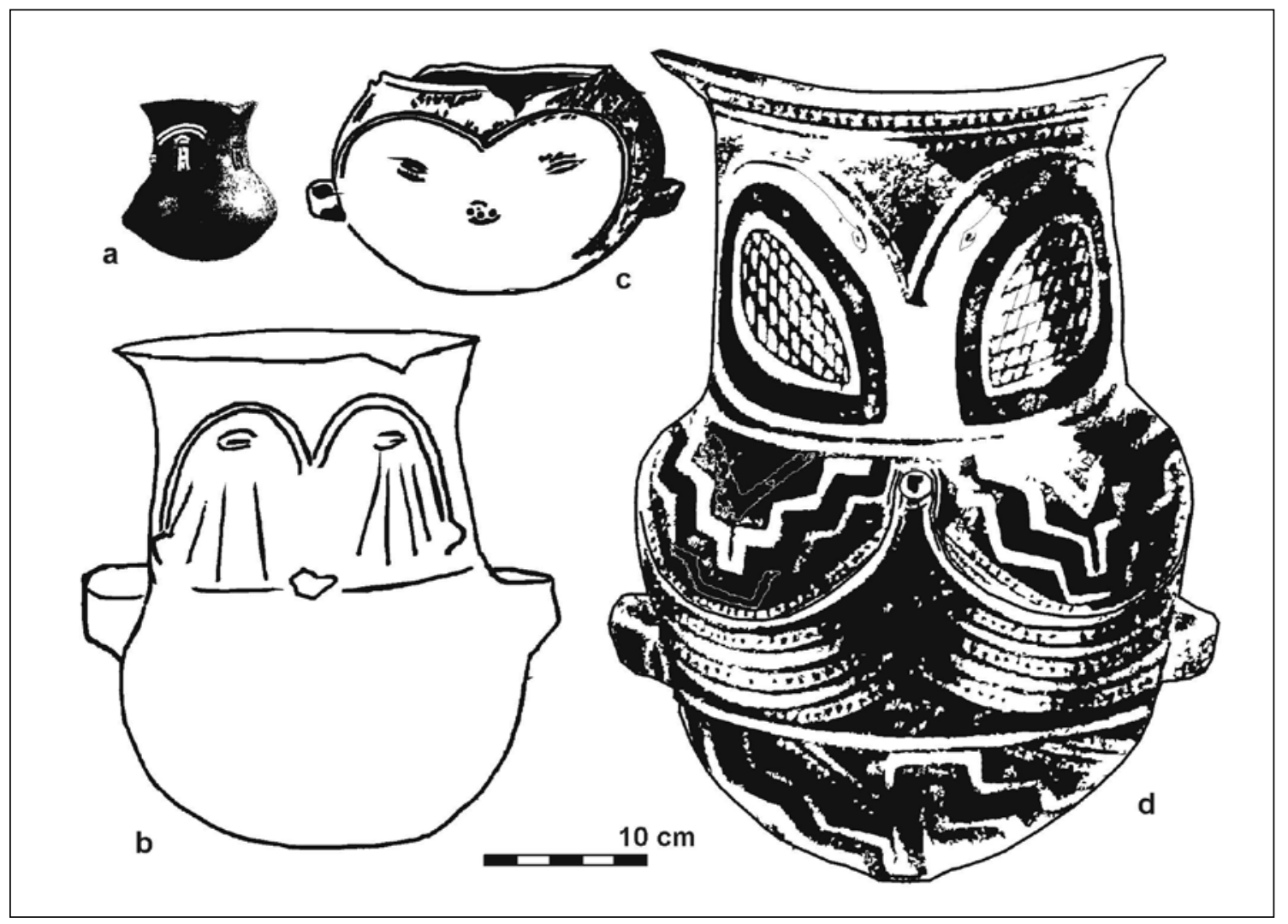

Figura 3. a) Vaso negro pulido, Amaicha ( $\mathrm{n}^{\circ} 100.680 \mathrm{Col}$. Zavaleta, Chicago); b) Vasija gris pulido, Cafayate ( $\mathrm{n}^{\circ}$ 6501/685/06 Col. Zavaleta, Berlín); c) Olla (cuello roto), Cafayate ( $n^{\circ} 88518$ Col. Schreiter, Viena; tomado de Becker-Donner 1951-52); d) Urna santamariana del Período Tardío (Museo Etnográfico). 


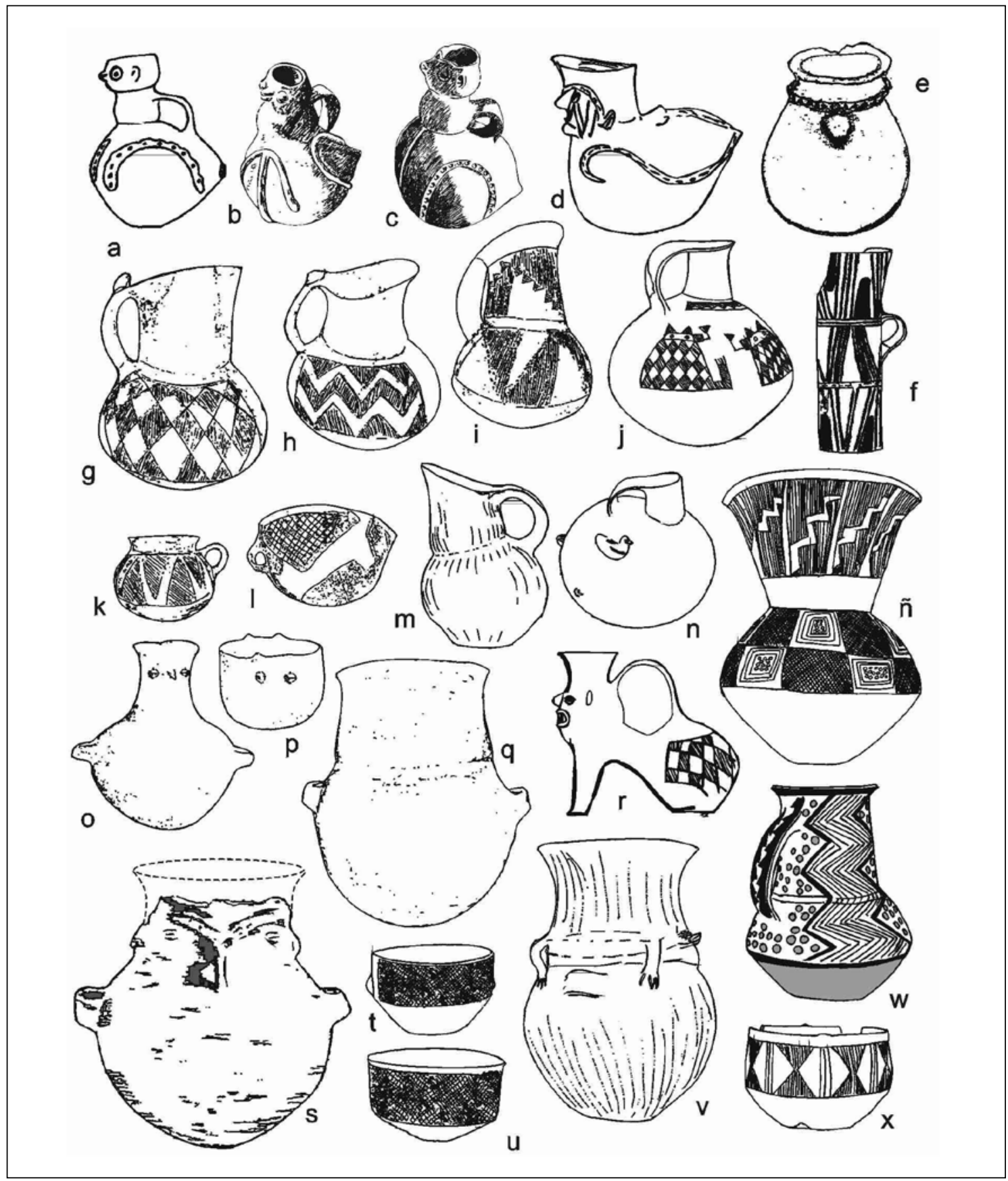

Figura 4. a) Vaso ornitomorfo, gris-pardo pulido, San Isidro, Cafayate ( $\mathrm{n}^{\circ} 100756$ Col. Zavaleta, Chicago); b) Ornitomorfo, Calchaquí Sur-Yocavil Norte (tomado de Becker Donner 1951-52); c) Ornitomorfo, Calchaquí Sur-Yocavil Norte (tomado de Becker Donner 1951-52); d) Vaso efigie, Quilmes ( ${ }^{\circ}$ 6409/685/06 Col. Zavaleta, Berlín); e) Olla con cordón aplicado y punteado, valle de Santa María (nº 1379 Col. Peirano, Instituto de Arqueología de Tucumán; f) Vaso Vaquerías rojo sobre ante, Chuscha, Cafayate (nº 138, Col. R. Bravo; tomado de Carrara y colaboradores 1961); g, h) Dos jarras vertederas, Lampacito (Scattolin et al. 2005); i) Jarra marrón vertedera, Lampacito (Scattolin et al. 2005); j) Botella con personajes fumando en pipa, Banda de Arriba, Cafayate (tomado de Lo Celso 2004); k, l) Olla y escudilla gris inciso, Lampacito (Scattolin et al. 2005); $\mathbf{m}, \mathbf{n}, \tilde{\mathbf{n}}$ ) Vasija rojo pulido liso y negro pulido con aplicaciones de avecillas y vasija compleja gris negra incisa, Banda de Arriba, Cafayate (Scattolin et al. 2005); o, q, s) Vasijas rojo pulido, Lampacito (Scattolin et al. 2005); p) Cuenco ante pulido, Lampacito (Scattolin et al. 2005); r) Antropomorfo, gris-negro inciso, El Bañado (tomado de Pelissero y Difrieri 1981); t, u) Cuencos incisos negros, Banda de Arriba y Santa María (Scattolin et al. 2005); v) Vasija rojo pulido, Banda de Arriba, (Scattolin et al. 2005); w) Vasija negro y rojo sobre blanco, Banda de Arriba, Cafayate (Scattolin et al. 2005); x) Cuenco inciso rojo, Banda de Arriba (Scattolin et al. 2005). No a escala. 
“... sabemos que la tendencia a la 'animación' de vasijas es universal. Sin duda, aquí está reforzada por la creencia, igualmente universal, en el poder 'apotropaico' de ojos o máscaras" (Gombrich 1999 [1979]: 259).

Ciertamente, podría considerarse también como una tendencia histórica -al parecer, un hábito- en Yocavil, debido a la afinidad manifiesta entre esta práctica presantamariana de construir vasijas con forma humana y la confección de las tan conocidas urnas funerarias santamarianas del Período Tardío con rostros sobre el cuello y brazos en arco sobre el pecho, muchas portando una pequeña vasija entre sus manos; lo cual sugiere investigar la existencia de cierta continuidad o fidelidad a determinadas fórmulas de confección de piezas en la trayectoria histórica del valle (Figura 3).

Las representaciones ornitomorfas siguen la misma modalidad de manufactura y tratamiento plástico decorativo y sugieren que el motivo del ave, por la aplicación de pequeñas alas o pico, es también un recurso iconográfico reiteradamente usado (Figura 4).

Hay otras características de la muestra que merecen atención por su alta popularidad. Las tres cuartas partes de los ejemplares son de contorno circular, pero la cuarta parte de ellos tiene contorno de simetría dorsoventral normalmente asociado al atributo vasija-efigie (Gráfico 3 y 4, Figura 4). Este alto índice en el uso de este recurso estilístico, que aludimos al principio del trabajo, es una cualidad de la muestra que merece resaltarse.

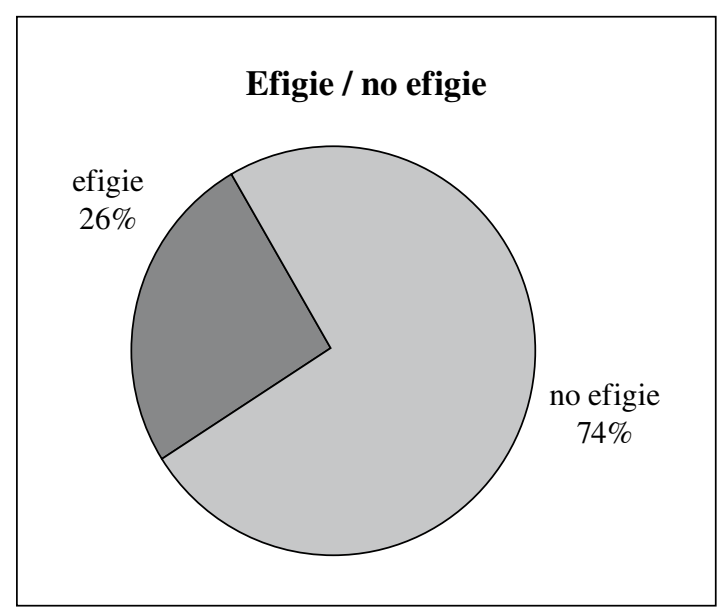

Gráfico 3. Efigie / no efigie.

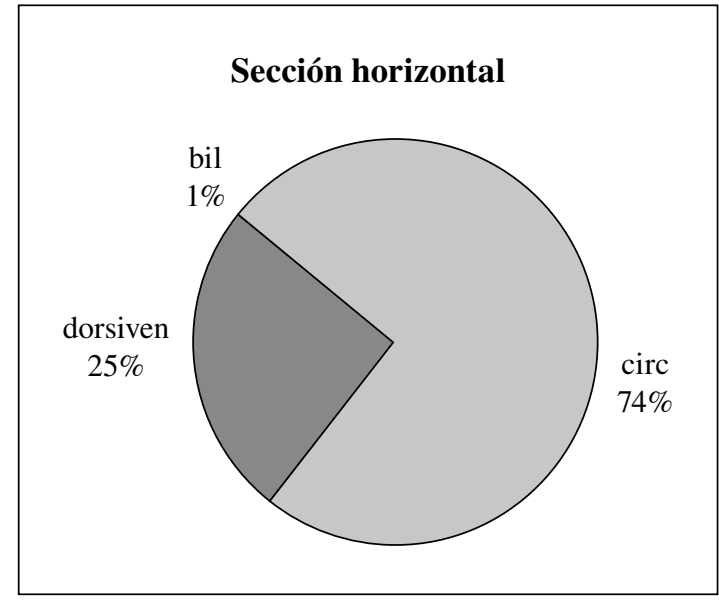

Gráfico 4. Sección horizontal.

\section{Cuello vertedero / no vertedero}

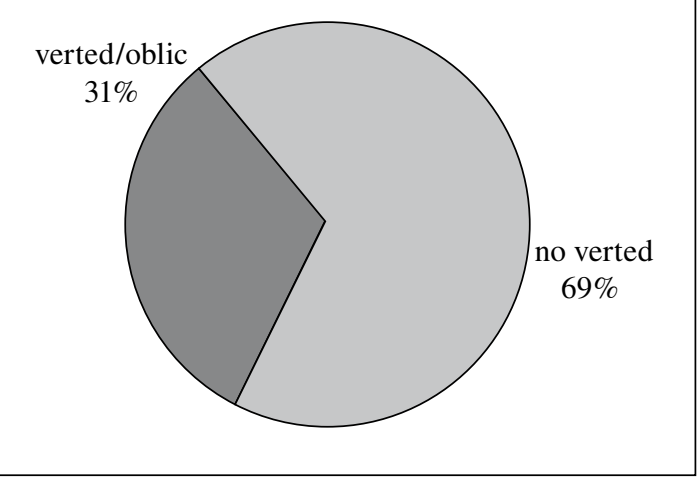

Gráfico 5. Cuello vertedero / no vertedero.

Otra propiedad estilística notable, es que de las 307 vasijas, 57 tienen cuello en posición inclinada o descentrada y borde oblicuo (vertedor) (18\% del total y $31 \%$ de las piezas con cuello, ver Gráfico 5 y Figura 4). Una gran parte de estas peculiares jarras vertedoras de gran popularidad son lisas, otras son vasijas efigie modeladas e incisas y otras llevan decoración incisa por sombreado zonal. Una pieza de perfil oblicuo procedente de El Bañado en el fondo del valle de Santa María, hoy en la colección de la Universidad de Rosario (Tarragó y Scattolin 1999: Fig. $2 \mathrm{~g}$ ), se asocia a una fecha radiocarbónica de 1375 \pm 40 AP (Ua-20627, 628-675 Cal. DC, 1 sigma). Heredia aisló esta particular silueta de simetría dorsoventral y cuello con borde desnivelado como propia del norte del valle de Santa María y del sur del valle Calchaquí, y consideró que representaba una 
"cultura" independiente que denominó San Carlos y que era parcialmente contemporánea y análoga a la cultura Ciénaga de Hualfín, pero distintiva de aquella región (Heredia 1974: 112; Heredia et al. 1974, cit. en Tarragó 1989: 468-471; Tarragó y Scattolin 1999: 143). ${ }^{5}$ Dos sitios funerarios recientemente conocidos en Lampacito y en Banda de Arriba de Cafayate reúnen varias decenas de vasijas de las cuales media docena son jarras vertedoras (Lo Celso 2004; Scattolin et al. 2005). Una fecha de $\mathrm{C}^{14}$ data a Lampacito entre fines del siglo VI y la primera mitad del siglo VII DC (AA-59414, 1446 \pm 36 AP; 595-655 Cal. DC, 1 sigma).

Con respecto a los diseños no figurativos, el uso de relleno o tramado zonado con técnica incisa parece ser bastante común, y este rasgo se comparte con otros estilos del primer milenio DC como Candelaria inciso y Ciénaga inciso (Gráficos 6 y 7). Varias de las piezas se presentan pintadas en negro sobre ante o rojo sobre ante con diseños geométricos. Otros diseños no figurativos se ejecutaron mediante incisión o grabado sobre piezas grises o casi negras como círculos u ovalillos incisos o grabados, rellenando áreas o entre líneas paralelas (Figura 5 a-f), que también se encuentran en piezas de estilo Candelaria de Pampa Grande (Ambrosetti 1906: Fig. 149-6).

Un número reducido de ejemplares presenta diseños no figurativos pintados en negro sobre ante o en negro y rojo sobre ante, de círculos, espirales u óvalos concéntricos, triángulos de lados curvos y polígonos rellenos de punteados o punteados entre líneas (Figuras 5, 6 y 7). Por ejemplo, en la colección Zavaleta-Chicago, hay dos piezas (Figura 5 j, k) con decoración no figurativa pintada en negro sobre ante $\left(\mathrm{n}^{\mathbf{o}} 100589\right)$ y en negro y rojo sobre ante $\left(\mathrm{n}^{\circ}\right.$ 100492) que fueron clasificadas como "Aguada

5 La definición por parte de Heredia de esta hipotética cultura arqueológica quedó inconclusa e inédita. Comunicó su proposición ante el III Congreso Nacional de Arqueología Argentina de 1974 en Salta. Al año siguiente Heredia fue separado de su cargo y se vio obligado a abandonar el país en 1976. A su vuelta en 1987 ya no retomó el estudio del Período Formativo en Santa María Norte-Calchaquí Sur y se volcó a la investigación en la región de Ambato. Falleció en 1989. Quizá por haber permanecido sin publicar, ni la evidencia ofrecida ni las ideas propuestas fueron incorporadas a los esquemas sintéticos corrientes de historia cultural del N.O.A. y mientras otras culturas prehispánicas quedaron reificadas por haber arraigado en el conocimiento escolar y popular, esta supuesta cultura concebida por Heredia se ha mantenido en estado de noción inadvertida.

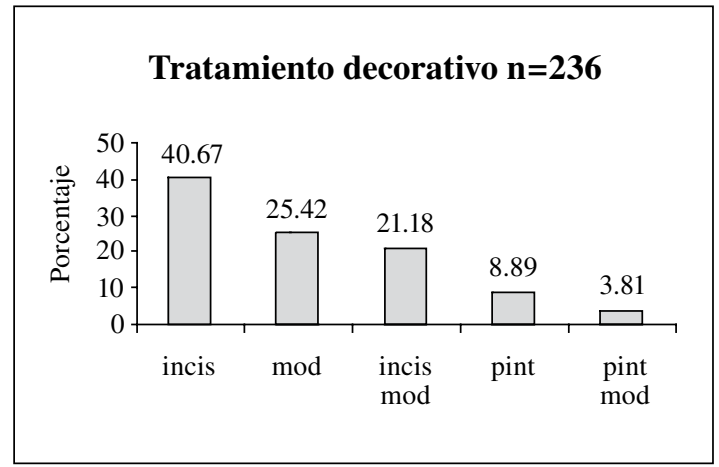

Gráfico 6. Tratamiento decorativo.

\section{Decoración fig/no fig $n=239$}

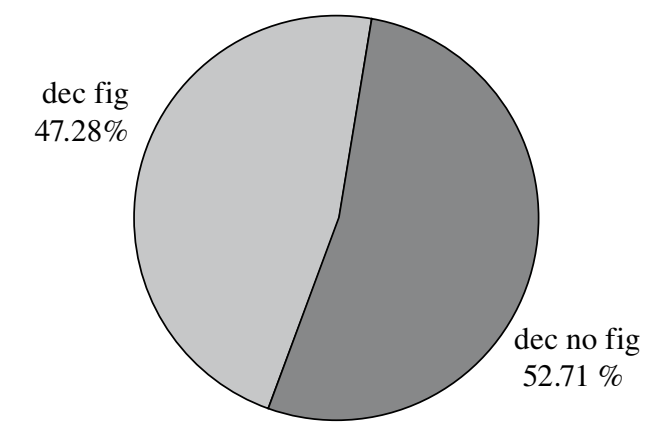

Gráfico 7. Decoración figurativa / no figurativa.

decadente"6 por A. R. González (Archivo Acc. 894, FMNH Chicago, 1973). Heredia quizá también las hubiera clasificado de esa manera, puesto que señaló haber hallado esta clase de fragmentos en el valle de Yocavil (Heredia et al. 1974 cit. en Tarragó y Scattolin 1999). Una similar cerámica pintada definida como Aguada bicolor ha sido encontrada en el sitio Morro del Fraile, y Aguada tricolor en

6 Con este término, González hacía referencia a las piezas cerámicas supuestamente más tardías que, luego del apogeo, representarían la declinación de la Cultura Aguada y donde ya no se reconocen en ellas las figuras felínicas completas sino sus atributos disgregados, particularmente óvalos de color pleno o reticulados, que González supone que representan las manchas del jaguar. Constituirían, para él, un tipo cerámico independiente (1964: 212, 221, 246; para una variante de esta idea, ver Sempé y Albeck 1981). Ciertas interpretaciones y designaciones de la Cultura Aguada por parte de González parecen estar modeladas, según las categorías de Bennett para Tiwanaku, sobre todo, en el uso que hace de los vocablos "clásico" y "decadente". 


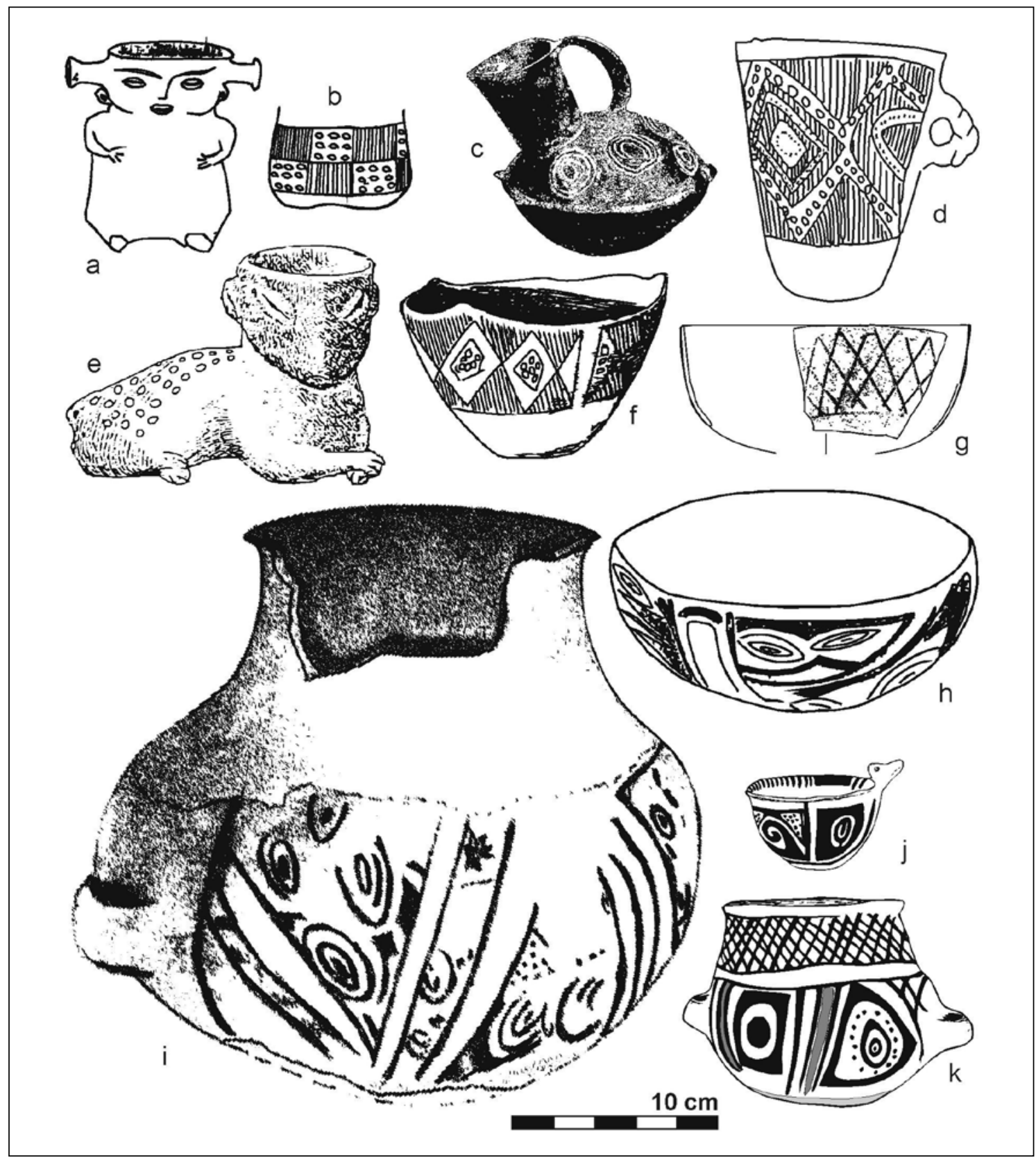

Figura 5. a) Personaje con modelados auriculares, gris-negro, Chuscha, Cafayate ( $\mathrm{n}^{\circ} 412$, Col. Bravo; tomado de Carrara y colaboradores 1961); b) Vista posterior de la misma vasija donde se aprecian dameros incisos rellenos de líneas y ovalillos; c) Vasija negra incisa, alrededores de Cafayate (Col. Bravo); d) Jarro alto gris negro inciso, valle de Santa María (Museo Etnográfico); e) "Felino manso" con ovalillos grabados, valle de Santa María (Col. Zavaleta, Chicago; tomado de Ambrosetti 1896-99); f) Escudilla gris de cuatro puntas con rombos incisos rellenos de líneas y ovalillos, Yocavil Norte-Calchaquí Sur Yocavil Norte-Calchaquí Sur (nº 88886, Col. Schreiter, Viena; tomado de Becker-Donner 1951-52); g) Escudilla incisa de Morro Espinillas; h) Escudilla Guachipas policromo (Col. Bravo; tomado de Carrara y colaboradores 1961); i) Cántaro Guachipas policromo, Divisadero, Cafayate, Quilmes (Museo de Quilmes); j) Cuenco pintado en negro sobre ante, Amaicha ( $\mathrm{n}^{\circ}$ 100589, Col. Zavaleta, Chicago); k) Vasija con decoración geométrica negro y rojo sobre ante, Yacochuya, Cafayate (n ${ }^{\circ}$ 100492, Col. Zavaleta, Chicago). 


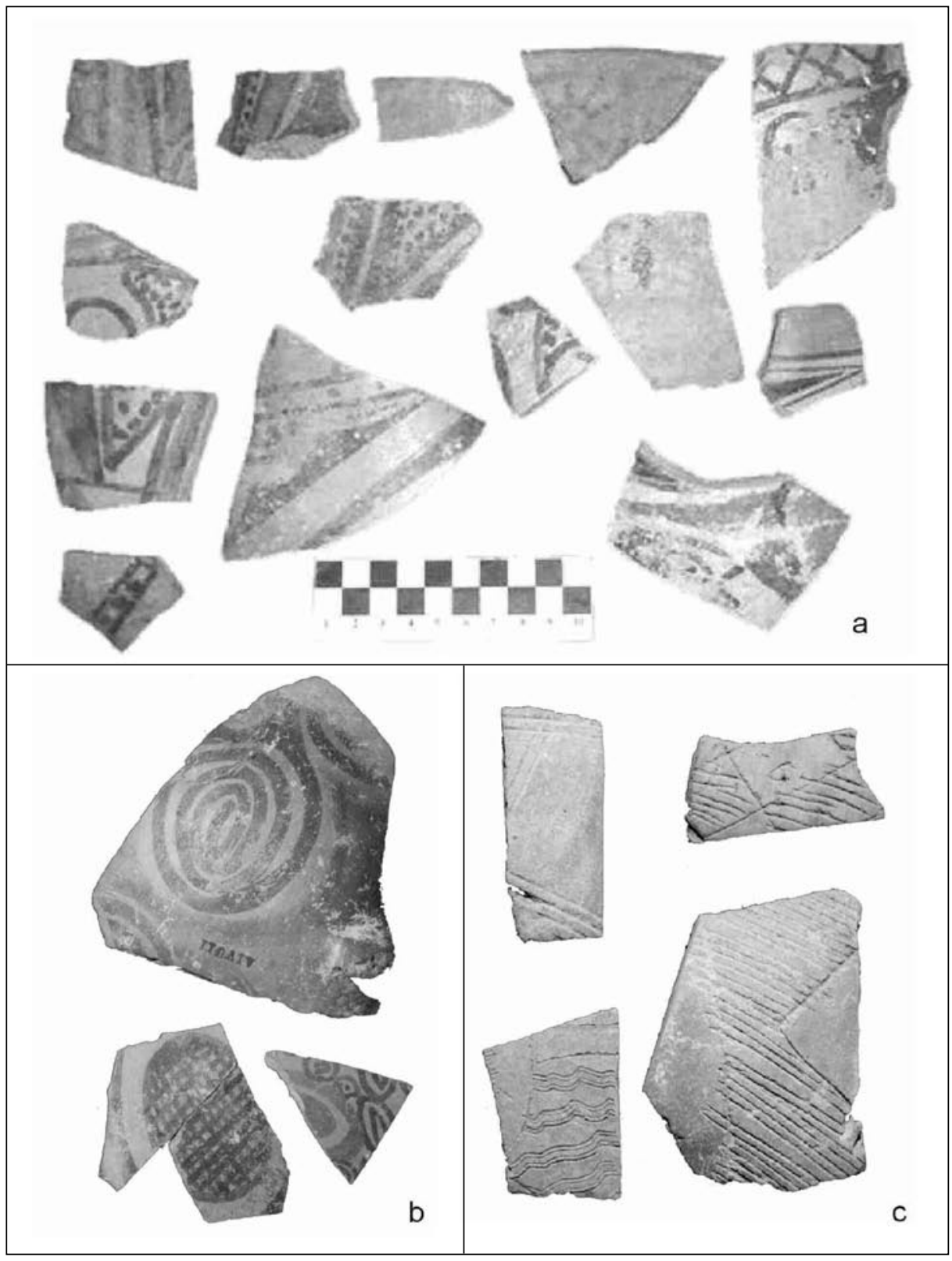

Figura 6. a) Fragmentos Guachipas policromo o Aguada decadente, Tolombón (Col. Aparicio, Museo Etnográfico); b) Fragmentos Guachipas policromo o Aguada decadente, valle de Santa María (Col. Museo Escuela de Antropología, Rosario); c) Fragmentos incisos o grabados (¿San Rafael grabado?), valle de Santa María (Col. Museo Escuela de Antropología, Rosario).

el sitio El Carmen-2, cerca de Quilmes (Nastri et al. 2006).

Por el contrario, Serrano (1966: 67) seguramente hubiera clasificado estas piezas bajo el rótulo "Guachipas policromo" que él distinguió para el norte del valle de Santa María y sur del valle Calchaquí ya que presentan atributos tales como "las curiosas figuras en forma de espinas de rosa", algunas rellenas de puntos (Figura $7 \mathrm{c}, \mathrm{g}$ ). Ocurre algo parecido en ciertos materiales fragmentarios recolectados en los años 40 por F. de Aparicio en Tolombón (Figura 6 a, Col. Aparicio, Museo Etnográfico); y el recientemente descubierto sitio Lázaro, también en Tolombón, con un recinto cercado que incluye varias plataformas de piedra en su interior, contie- 


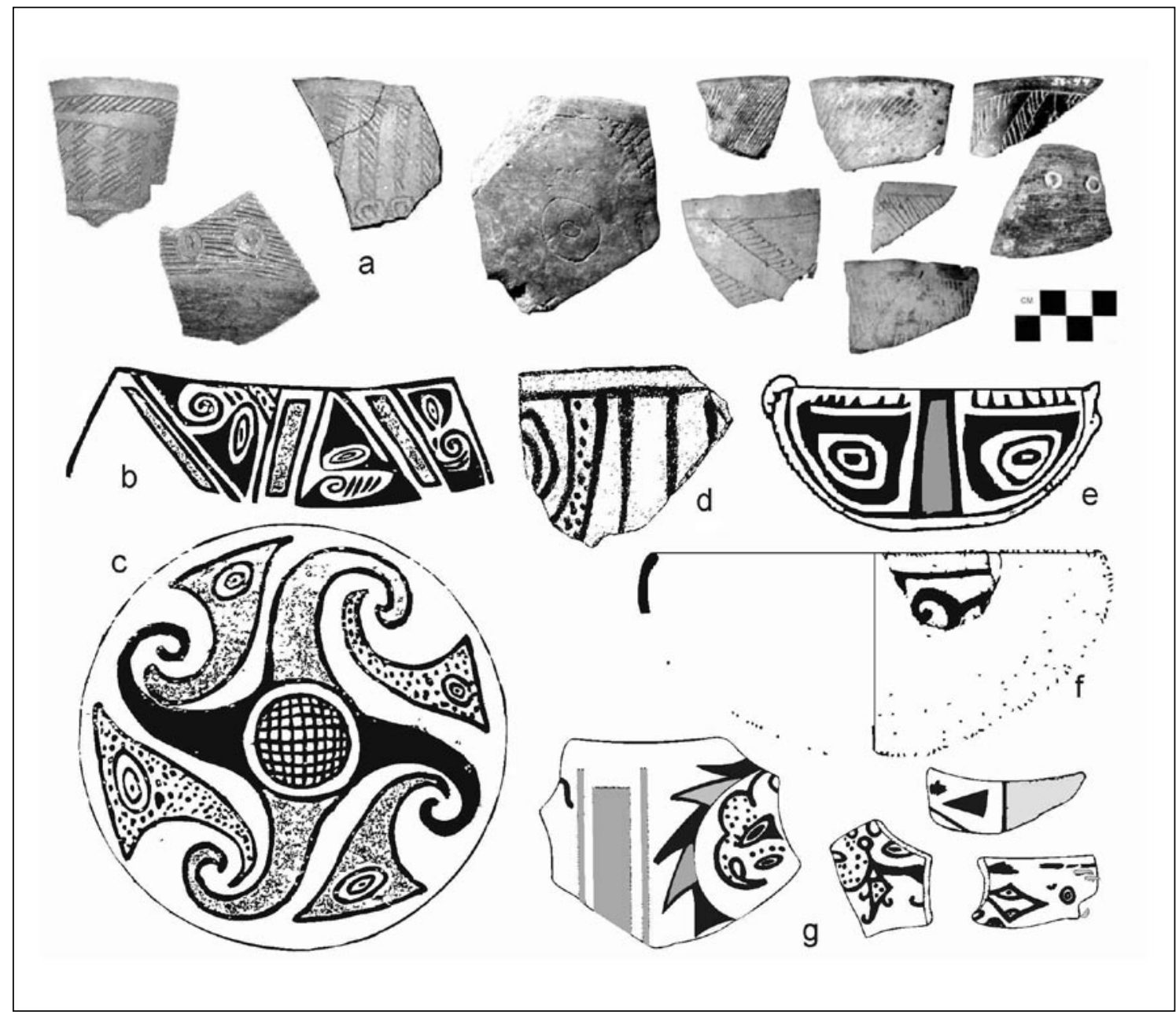

Figura 7. a) Fragmentos incisos o grabados (San Rafael grabado, Candelaria grabado, etc.), del valle Yocavil; b y c) Fragmentos Guachipas policromo (tomado de Serrano 1966); d) Fragmento de Tebenquiche (tomado de Krapovickas 1955); e) Escudilla de Coyo, San Pedro de Atacama (tomado de Costa y Llagostera 1994); f) Fragmentos San Rafael pintado del valle Calchaquí (tomado de Raffino y colaboradores 1982); g) Tiestos Rupachico policromo, Rupachico (tomado de Heredia 1974).

ne cerámica de superficie semejante a "los estilos definidos por Serrano como Guachipas policromo o a un Aguada pintado local...” (Williams 2003: 171). Además, esta cerámica tiene atributos que comparte con el tipo San Rafael pintado definido para el valle Calchaquí por Raffino y colaboradores (1982: Lámina I: 2, 6 y 7). Fragmentos con características semejantes fueron designados por Heredia como tipo Rupachico policromo, para las yungas orientales (Heredia 1974). Tales rasgos constituyen un modo estilístico que estuvo en uso en el valle Yocavil y varias zonas aledañas. En efecto, algunas vasijas similares a estas se habrían utilizado también en sitios de la puna como Tebenquiche o San Pedro de Atacama (Figura 7 d, e; ver Krapovickas 1955 :
29, Fig. 6; Costa y Llagostera 1994: 84). Según Krapovickas (1955: 30):

"La identidad de los dibujos es tal, que podríamos decir que nuestro ejemplar de Tebenquiche y los de Tolombón, si bien no han pertenecido a la misma pieza, habrían sido partes de vasos completamente iguales".

A pesar de la proliferación de designaciones para un mismo hábito estilístico, los investigadores mencionados coinciden en ubicar cronológicamente esta tendencia decorativa y de confección hacia la parte final del primer milenio DC. Los motivos decorativos "en espinas de rosas" o los punteados, 
triángulos de lados curvos y volutas, que aparecen en estas piezas de la Colección Zavaleta, no se han referido para el estilo Aguada policromo o clásico (por oposición al "decadente").

De los más de 300 ejemplares estudiados sólo existe un único caso de vasija confeccionada en el estilo Aguada gris grabado definido para Hualfín, el cual lleva la representación de un personaje antropofelínico (Korstanje 1988). Ninguna pieza presentó la imagen del "guerrero" o "sacrificador" ni de "trofeos de cabezas". Y, por otra parte, las figuras felínicas no son muy afines a las imágenes emblemáticas de tal animal en los contextos de Hualfín o Ambato. En las colecciones estudiadas hay dos únicas imágenes de una "llama felinizada" en jarras grises incisas. También hay un "tigrillo" con fauces, algo tosco y con un asa retorcida. Ciertas cualidades "felínicas", agresivas o de ferocidad, se observaron en dos piezas gris-negras incisas de El Bañado obtenidas una por Bruch (1911: Fig. 25) y otra por Pelissero y Difrieri (1981: Fig. 6), pero nadie las describe con la denominación "Aguada". Por último, hay una hermosa efigie de un felino modelado y con manchas figuradas con círculos o pequeños óvalos incisos que parece representar un tierno cachorro en reposo con sus patas delanteras cruzadas y que puede describirse como un "felino manso" (Figura 5e), por carecer de los atributos de ferocidad que caracterizan a su contraparte de Hualfín y Ambato: fauces, garras, postura agresiva (Ambrosetti 189699: 533, Fig. 33). Así que respecto a la presencia de la imaginería del estilo Aguada hay que concluir que, en esta muestra, el "guerrero-sacrificador" está ausente y el "felino" o "uturunco" es notable por su escasez y excepcionalidad. Y debe recordarse que, al menos en Santa María, los óvalos y espirales pintados también forman parte de la figura de la serpiente o del ave, y no son atribuibles exclusivamente a la del felino.

\footnotetext{
Ahora bien, dicho esto, debe reconocerse ciertamente que hay algunos ejemplares en otras colecciones que portan la imagen del "dragón", ya mencionados por varios autores. Por ejemplo, en la colección de Tolombón recogida por Krapovickas y Lafón para el Museo Etnográfico, hay una escudilla ( $n^{\circ}$ 56-1) con representación de un "lagarto" o "dragón" de cuerpo vermiforme y lengua bífida, pero no es un "uturunco" (González y Baldini 1991: Fig. 3d). De la misma colección, un minúsculo fragmento forma parte de una representación del "guerrero", pero está muy incompleta (Tarragó y Scattolin 1999: 147, Fig.
}

2e). Una sola escudilla muestra un antropomorfo con tocado felínico (Müller 1997-98). Por todo esto, el número de estas piezas de estilo Aguada en Yocavil no es comparable al de los conjuntos de más al sur. Al momento, conocemos menos de una docena de vasijas enteras de estilo Aguada con procedencia de todo el valle de Santa María, y parecen corresponder a microestilos regionales distintos (Tabla 2). Este comportamiento sugiere que varias de esas piezas de estilo Aguada en su modalidad figurativa pueden haber sido confeccionadas fuera de Santa María y trasladadas allí desde distintas direcciones, lo que habrá que verificar. Un fenómeno tal de aparición esporádica de piezas de estilo Aguada (y otros) fuera de sus áreas originales de producción también ocurre en otras regiones del Noroeste Argentino y del norte de Chile, como en San Pedro de Atacama, donde se ha hallado cierta cantidad de artefactos de dicho estilo (Tarragó 1989).

Por otra parte, entre las alfarerías que se encuentran en menor cantidad hay piezas de estilo Vaquerías y Condorhuasi (Figura 4f). En Banda de Arriba de Cafayate (Lo Celso 2004) se encontró una jarra de un estilo innominado, pero muy idiosincrásico, pintada en negro y rojo sobre blanco, con diseños de haces de líneas paralelas y lunares (Figura 4w). Jarras "hermanas" de ésta han sido halladas en Cachi, valle Calchaquí (no 10672 de la Colección Zavaleta-Buenos Aires, Museo Etnográfico), en el valle de Lerma en Salta (Navamuel 1979) y en San Pedro de Atacama en Chile (Tarragó 1989: 431), donde han sido datadas por termoluminiscencia en $1360 \pm 100$ AP (620 DC), en la tumba 4534 de Toconao Oriente (Berenguer y colaboradores [1986: 32-33, Fig. 17] señalan su posible procedencia de Tarija), y hay también ollas y escudillas en las tumbas de Sequitor Oriental 1647 y 1682 y una jarra en Larrache Callejón 1719 (Tarragó 1989: 431, Fig. 55.9).

\section{Sumario de las observaciones}

Si estos 300 recipientes pueden tomarse como una muestra representativa de la alfarería "fina" durante el primer milenio DC, las poblaciones de Yocavil, sobre todo, en su sección norte, recurrieron habitualmente al uso de unos medios estilísticos, motivos decorativos, gestos motores, diseños técnicos y formas de confeccionar vasijas que incluyen:

- Elaboración frecuente de vasijas efigie o prosopomorfas. 


\begin{tabular}{|c|c|c|c|c|}
\hline & Descripción & Colección & Procedencia & Referencia \\
\hline 1 & $\begin{array}{l}\text { "Vaso curioso" de Santa María, según Lafone Quevedo. } \\
\text { Pintura policroma con motivo de cuerpo serpentiforme } \\
\text { relleno de óvalos. Lengua bífida (¿?). }\end{array}$ & $\begin{array}{l}\text { Museo Nacional, según } \\
\text { Lafone ¿hoy en Museo } \\
\text { Etnográfico? }\end{array}$ & Santa María & $\begin{array}{l}\text { Lafone Quevedo 1908: } \\
\text { 367, Fig. } 41 \text {. }\end{array}$ \\
\hline 2 & $\begin{array}{l}\text { Olla negra grabada con cuatro "dragones". Cf. piezas } \\
\text { de vertiente oriental: Ambato, Tafí, Rupachico. }\end{array}$ & $\begin{array}{l}\text { Col. Lafone Quevedo, } \\
\text { Museo de La Plata. }\end{array}$ & Santa María & $\begin{array}{l}\text { Lafone Quevedo 1908: } \\
\text { Planchas V y VI. }\end{array}$ \\
\hline 3 & $\begin{array}{l}\text { Escudilla con diseño de cuerpo serpentiforme con } \\
\text { óvalos, cabeza antropomorfa con corona. Interior } \\
\text { con un pájaro. Policromo. "Puco Quiroga" según } \\
\text { Lafone Quevedo. }\end{array}$ & $\begin{array}{l}\text { Museo Etnográfico } \\
\mathrm{n}^{\circ} 12411 .\end{array}$ & Amaicha & $\begin{array}{l}\text { Ambrosetti 1896- } \\
\text { 99: Fig. 56; Lafone } \\
\text { Quevedo 1908: 368, } \\
\text { Fig. 42; Bregante } \\
\text { 1926: 102. }\end{array}$ \\
\hline 4 & $\begin{array}{l}\text { Escudilla policroma con dragón. Cuerpo vermiforme. } \\
\text { Boca abierta con lengua múltiple. }\end{array}$ & $\begin{array}{l}\text { Col. Krapovickas y Lafón. } \\
\text { M. Etnográfico n }{ }^{\circ} \text { 56-1. }\end{array}$ & Tolombón & $\begin{array}{l}\text { González y Baldini } \\
\text { 1991: Fig. 3d. }\end{array}$ \\
\hline 5 & $\begin{array}{l}\text { Jarro timbal policromo. Motivo de cuerpo serpenti- } \\
\text { forme con óvalos. Boca con lengua bífida. }\end{array}$ & $\begin{array}{l}\text { Col. Vázquez, Sta. María. } \\
\text { Se desconoce su paradero } \\
\text { actual. }\end{array}$ & Andalhuala & $\begin{array}{l}\text { Serrano 1966: Lám. } \\
\text { XXVIII } 2 .\end{array}$ \\
\hline 6 & $\begin{array}{l}\text { Escudilla Aguada gris grabado con un personaje } \\
\text { antropo-felínico. }\end{array}$ & $\begin{array}{l}\text { Instituto Arqueología y } \\
\text { Museo, Tucumán } \\
n^{\circ} 4974 \text { MA0844. }\end{array}$ & $\begin{array}{l}\text { Valle de Santa } \\
\text { María }\end{array}$ & $\mathrm{Kc}$ \\
\hline 7 & $\begin{array}{l}\text { Olla grande esférica, pintada con decoración geomé- } \\
\text { trica y con rostro antropomorfo con ojos de óvalos } \\
\text { espiralados con lágrimas. }\end{array}$ & $\begin{array}{l}\text { Col. Lafone Quevedo, } \\
\text { Museo de La Plata. }\end{array}$ & $\begin{array}{l}\text { Punta de } \\
\text { Balasto }\end{array}$ & $\begin{array}{l}\text { Lafone Quevedo } 1908 \\
\text { Plancha VIIa. }\end{array}$ \\
\hline 8 & $\begin{array}{l}\text { Olla negra grabada con antropomorfos y zoomorfos } \\
\text { con fauces. Cf. piezas de vertiente oriental: Ambato, } \\
\text { Rupachico, Tafí. }\end{array}$ & $\begin{array}{l}\text { Museo Laterano, } n^{\circ} 9676, \\
\text { Roma. }\end{array}$ & Santa María & $\begin{array}{l}\text { Müller 1997-98: } \\
\text { Fig. 1. }\end{array}$ \\
\hline
\end{tabular}

Tabla 2. Vasijas enteras de estilo Aguada policromo y Aguada grabado halladas en Yocavil.

- Elaboración de recipientes con contorno de simetría dorsoventral, aparte del común contorno circular.

- Aplicación de un cuello vertedor, de inserción inclinada y de perfil oblicuo, en alta proporción, aparte del común cuello en posición centrada vertical y borde recto horizontal.

- Representaciones antropomorfas frecuentes, preponderantemente modeladas: cuerpos, rostros, rasgos aislados del rostro, indicaciones de trenzas, extremidades superiores en mayor proporción que inferiores; en caso de indicación de sexo, hasta ahora, hay más ejemplares femeninos que masculinos.

- Representaciones ornitomorfas frecuentes manifestadas en la conformación de la vasija misma $\mathrm{y}$ en el modelado de picos y alas.

- Confección de producciones de alfarería fina en diferentes clases o series: una gris, gris-negra y negra y otra ante, beige y rojiza, cuyas distintas frecuencias podrían desplegar diferencias temporales, siendo la gris-negra bastante habitual en la primera parte del primer milenio DC mientras que la pasta sin inclusiones y la fina terminación de color rojo ladrillo pulido ocurre sobre todo en la segunda parte del primer milenio DC.
- Alta frecuencia en el empleo de incisión con instrumento de punta simple, comúnmente punteado, rayado y reticulado zonado. También alta frecuencia de modelado-pastillaje y menor incidencia de diseños pintados (con variaciones temporales).

- Escaso empleo de incisión de rellenado zonado con instrumento de punta múltiple (peine) a diferencia de lo que ocurre de modo común en el estilo Ciénaga de Hualfín; y débil tendencia a recurrir al motivo del felino y al motivo antropomorfo del guerrero, definidos para el estilo Aguada de Hualfín.

- Decoración pintada de óvalos concéntricos, punteados de relleno, triángulos de lados curvos y volutas en colores negro y/o rojo sobre pasta natural de cocción oxidante, posiblemente en la segunda parte del primer milenio DC.

Es importante recalcar que el conjunto analizado no se ciñe a un solo estilo unitario y muy convencionalizado, fácilmente codificable, sino que más bien parece incorporar piezas de diferentes modalidades. Por esta y otras razones no puede asumirse que todos los recipientes estudiados sean de exclusiva fabricación local; algunos debieron provenir de regiones vecinas. Por eso tales vasijas parecen referir a la 
esfera del consumo local más que a la esfera de la producción local. A fin de resolver estas cuestiones habrá que realizar otras tareas. En una primera instancia, con el presente trabajo, hemos considerado las tendencias más habituales, las propiedades más recurrentes y las regularidades más abundantes en el uso de ciertos atributos cuyos ejemplos puedan ser comparados con objetos que tengan procedencias locales y asociaciones seguras, bien registradas y, en lo posible, fechadas. Al momento se están detectando nuevos lugares con unidades arqueológicas formativas que contienen recipientes completos asociados en un mismo contexto (Aschero y Ribotta 2004 Ms; Lo Celso 2004; Scattolin et al. 2005), lo cual no ha sido muy usual. A dicha comparación podrán sumarse oportunamente análisis más precisos de pastas cerámicas, de procedencia de materias primas y de hábitos motores en el diseño de artefactos, es decir, elementos que proveen mejores indicadores de identidad/alteridad cultural (Shennan 1989; Washburn 1989; Gosselain 2000).

\section{De los modelos cronológico cultural y de legitimación simbólica}

Frente a la escasez de elementos de estilo figurativo Aguada y ante la presencia de algunos atributos locales de uso frecuente hay que considerar las limitaciones de una transposición del modelo cronológico y desarrollo cultural desde Hualfín a Santa María. En primer lugar, este comportamiento lleva a pensar que, en términos prácticos, puede ser muy significativo hallar los motivos figurativos del sacrificador y del felino, pero la expectativa de que aparezcan en los sitios habitacionales de Santa María es escasa. En conjuntos de superficie examinados durante prospecciones regionales su presencia puede servir de indicador temporal, pero su ausencia puede obedecer a causas distintas del tiempo. En este caso, atributos tales como los pulidos especiales, proporción de pastas oxidantes/reductoras, grado de control en la cocción, técnicas y tipos particulares de incisiones, círculos concéntricos pintados o grabados y otros atributos decorativos menos llamativos y no figurativos serían más convenientes, si se quisiera detectar el último tramo del primer milenio DC en Yocavil.

Por otra parte, si los nombres de tipos desarrollados para una región se importan a menudo a otra sin que se haya demostrado que sean aplicables, entonces las clasificaciones cerámicas pueden acarrear problemas. Tomar prestadas directamente las tipologías desde Hualfín-Alamito -sin previo análisis de su aplicabilidad- podría causar confusión cuando se aplican más al norte, como en Santa María-Calchaquí. Así, este empleo incontrolado de tipologías puede conducir a que se asuma que los habitantes de Santa María fueron influidos intensamente por grupos de más al sur. Sin embargo, "el origen del cambio cultural raramente se somete a comprobación y la dirección putativa de la influencia cultural" en la historia prehispánica puede quedar (falsamente) "determinada por el lugar en que los nombres de tipos fueron definidos por primera vez por los arqueólogos" (Chilton 1999: 45). Ello debe tomarse en consideración en tanto todavía son poco conocidas y, sobre todo, escasamente ilustradas las cerámicas pretardías de varias regiones alrededor de Yocavil, como el valle de Lerma, el valle Calchaquí medio y sur, la región puneña adyacente, la llanura chaco-santiagueña, entre otras, lo que conspira para balancear el peso de distintas tradiciones estilísticas en el conjunto de los bienes culturales de Yocavil.

El análisis de estas colecciones puede ser una vía para contrastar hipótesis como la de una "ocupación de un espacio bastante continuo" por parte de la entidad o Cultura Aguada -como "manifestación de una integración a nivel de superestructura" (Núñez Regueiro y Tartusi 1993) - que incorporó al valle de Santa María y Calchaquí y también la reciente idea sobre la presencia de unas "colonias Aguada" en Yocavil, según un modelo de "archipiélago", radicadas para explotar "importantes yacimientos de mica" (Tartusi y Núñez Regueiro 2001). En este sentido las colecciones de artefactos, aún sin contexto, podrían ser un medio de prueba preliminar -limitado, pero disponible- para comenzar a efectuar contrastaciones indispensables, antes de que interpretaciones aún no verificadas se conviertan en conocimiento arraigado.

Respecto a los argumentos evolutivos que sustentan la división en períodos, habrá que interrogarse sobre los límites de la legitimación simbólica a través de representaciones iconográficas. Como se sabe, las sociedades aldeanas del N.O.A. son actualmente motivo de investigación acerca de su relativa complejidad, desigualdad, surgimiento de instituciones políticas hereditarias, instauración de señoríos, entre otros (Núñez Regueiro y Tartusi 1990, 2002; Pérez Gollán 2000). Dichas discusiones se fundan en la presencia de rasgos arquitectónicos, como la construcción de centros ceremoniales, la concentración demográfica, la especialización artesanal y la 
difusión de ciertas ideas religiosas evidenciada en una iconografía característica, rasgos que habrían tenido como centro innovador e integrador a la zona de Ambato, Hualfín y/o Alamito (según distintas interpretaciones) más o menos durante la época de Tiwanaku en los Andes Centro Sur (Núñez Regueiro y Tartusi 1993; González 1998; Pérez Gollán 2000). Es decir, se postula una escalada autónoma de complejización social, un origen autóctono de desarrollo evolutivo hacia la desigualdad social hereditaria. Hacia 1990 fue acuñado el término "Período de Integración Regional"7 -que suplantó al de Período Medio- precisamente para contrarrestar el sesgo difusionista de anteriores interpretaciones y subrayar la autarquía. En esta resignificación del concepto, los motivos iconográficos del personaje de los dos cetros, el guerrero o sacrificador, los jaguares acollarados y rampantes, entre otros, no indicarían la influencia centrífuga de Tiwanaku, sino una ideología y una religión compartidas por toda la extensión desde el Titicaca a Catamarca (Núñez Regueiro y Tartusi 1990, 2002; Pérez Gollán y Heredia 1990; Pérez Gollán 1991). Por eso habrá que examinar si los iconos representados en las vasijas de estilo figurativo de Aguada habrían sido en Yocavil igualmente válidos como referentes de legitimación, y si la acción simbólica del "sacrificador" con sus armas cortantes y punzantes, y sus trofeos de cráneos, habría tenido los mismos efectos que se dice que tuvieron en Hualfín, Ambato y otros valles del sur.

Confrontadas al presente análisis, tales proposiciones llevan a interrogarse acerca de la extensión y grado que alcanzaría, si es que lo hace, en el ámbito de Yocavil, la "integración ideológica" que se postula para el Período de Integración Regional, en tanto se la entienda como un fenómeno originado e impulsado, de manera precoz, desde las poblaciones de más al sur y sobre gran parte del N.O.A. (Pérez Gollán 2000; Núñez Regueiro y Tartusi 2002). Según la muestra analizada en esta ocasión, los iconos en Yocavil hacen referencia a un universo peculiar: vasijas prosopomorfas, rostros en relieve con tatuajes o lagrimones, aves con alas desplegadas, figuras con brazos activos o en descanso, algunas mujeres. Escasamente aparece aquí el estilo Aguada tal como se lo concibe en Hualfín o Ambato. En

\footnotetext{
7 Cuyos jalones temporales están todavía en debate, podrían ser tanto de 600 a 1100 DC (Gordillo 2004; Marconetto 2005) como de 300, 400 ó 500 a 900 DC (González 1998: 68; Pérez Gollán 1998; Gordillo 1999).
}

cambio, parece más bien que el estilo Guachipas distinguido por Serrano (1966), o lo que Heredia (1974) consideró como el estilo Aguada decadente, se utilizó con cierta frecuencia en Yocavil. La "obsesión felínica" (González 1964: 332) no es un fenómeno que se manifieste en la muestra que analizamos. El temible "sacrificador" es una figura aún menos invocada. Si las representaciones icónicas del guerrero-sacrificador y el "uturunco" en la cerámica de Ambato-Hualfín operaron como medios de legitimación simbólica, en la cerámica de Santa María ese recurso no fue usado. No hubo alta demanda de tales imágenes. Incluso los óvalos concéntricos y espirales pintados, al menos cuando son hallados en Yocavil, no pueden atribuirse exclusivamente o proyectarse maquinalmente como la metonimia del felino del estilo Aguada de Ambato-Hualfín. Por eso, ante la escasez de las imágenes pujantes y agresivas del estilo cerámico Aguada, estimo que los fundamentos que rigen la legitimación simbólica a través de la cultura material, tal como se postulan para Ambato o Hualfín difieren, de los que se dan en Yocavil. Y sería bueno averiguar si esta distinción se expresaba, además, en otros aspectos del mundo material aparte de las vasijas presentadas aquí.

Por otro lado, si la entidad o cultura que se conoce bajo el término de "Aguada", durante el lapso denominado Período de Integración Regional o Medio, presenta el carácter jerárquico e ideológicamente integrador y dominante que proponen diversos investigadores, habría que establecer en cuáles circunstancias dejaría de ser eficiente la causa de su dominio, cómo y por qué dejarían de sentirse sus efectos y cuáles estrategias pudieron haber eludido el crecimiento de tal poder. En este sentido, la variedad de recursos estilísticos usados durante el primer milenio DC pueden ayudar a comprender la diversidad de estrategias desplegadas en el uso de recursos plásticos y estilísticos y en las "elecciones tecnológicas" (Lemmonier 1992: 17) para la confección y decoración de la cerámica u otras artesanías. Sin embargo, el valor de tales recursos dependerá del contexto o campo de los bienes culturales en que se hayan puesto en juego, y las reglas de uso cambiarán, según las estrategias de los agentes. Valor de los recursos y carácter del campo se especifican mutuamente en el estudio empírico. Por eso, no podemos establecer de entrada, antes del análisis contextual sociohistórico, si, por ejemplo, los motivos decorativos no representacionales (Aguada decadente, Aguada bicolor, Guachipas policromo, San Rafael pintado, 
Rupachico policromo, etc.), reflejan una carencia o decadencia estilístico-tecnológica o constituyen una denegación preferencial de la decoración figurativa. Es decir, desde esta perspectiva, quedan todavía por establecerse los principios y los límites de la legitimación tanto en términos empíricos como teóricos.

Los resultados de nuestro examen revelan la existencia de recursos estilísticos y hábitos de diseño similares entre los materiales cerámicos procedentes de los valles de Santa María, de Tafí, del Cajón y sur del valle Calchaquí, aparte de rasgos comunes en el patrón de asentamiento. Además, un hecho que no se había enfatizado hasta ahora es que estos ámbitos también comparten atributos cerámicos con la cuenca de Tapia-Trancas y el área de La Candelaria, algo comprensible, puesto que son ámbitos vecinos. ${ }^{8}$ Por el momento, no sabemos si la variación cultural espacial que se detecta en los materiales, artefactos y estilos consumidos a través de la cuenca de Tapia-Trancas y los valles de Tafí, de Santa María, del Cajón y sur del valle Calchaquí durante la segunda parte del primer milenio es mayor o menor que la variación cultural espacial que se detecta entre los valles de Catamarca, de Ambato, de Hualfín y de Abaucán durante un lapso similar y para la cual se invoca un fenómeno de integración. Ello, aparte de que desconocemos cuál es la medida de integración/ fragmentación cultural que se ha aplicado para determinar que la llamada "Cultura Aguada" es una, y que las denominadas "culturas Candelaria y Tafí" son dos, siendo las tres por varios siglos contemporáneas. Ello sugiere reconsiderar cuál es el grado real de integración/fragmentación así como de complejidad social que efectivamente afecta a las poblaciones consumidoras de objetos de estilo Aguada y aquellas consumidoras de objetos de estilo Candelaria-Tafí. Y el conocimiento presente todavía no permite discernir -hasta tanto

8 Desde el valle de Santa María toma varias horas llegar a pie al valle del Cajón en el oeste y lo mismo a la vecina vertiente oriental de las yungas. Unos $50 \mathrm{~km}$, en línea recta, separan Cafayate de Pampa Grande. Unos 40 km separan Tolombón de Rupachico. En cambio, unos $150 \mathrm{~km}$ se extienden entre el centro del valle de Santa María y el valle de Hualfín (ver Figura 1). no se encare un análisis espacial exhaustivo- si tales rasgos variables responden a un modelo de distribución de rasgos continua o discontinua y tampoco distingue "si las distribuciones de artefactos se solapan al azar o si lo hacen de un modo no aleatorio formando agrupamientos distintivos" (Hodder 1982: 7).

Por otra parte, este estudio sugiere que la transmisión cultural y el uso de estilos cerámicos a través el tiempo en la región de los valles del Noroeste Argentino puede haber operado según diferentes estrategias por parte de distintos agentes sociales. Y por esta razón, las trayectorias de cambio de los medios estilísticos pueden haber tomado diversas direcciones y haberse expresado en las distintas variantes formales elaboradas por las alfareras y alfareros a través de la región.

Agradecimientos A las autoridades y curadores de las colecciones estudiadas: Jonathan Haas y Gary Feinman, del Field Museum of Natural History de Chicago; Jette Sandahl y Adriana Muñoz, del Världskulturmuseet de Gotemburgo; Jorgelina García Azcárate y Carlos Aschero, del Instituto de Arqueología y Museo de Tucumán; María Teresa Carrara, del Museo de la Escuela de Antropología de Rosario; José Antonio Pérez Gollán, del Museo Etnográfico de Buenos Aires; Rodolfo Raffino, del Departamento Arqueología del Museo de Ciencias Naturales de La Plata; Marie Fauvet-Berthelot, del Musée de l'Homme de París. Al Departamento de Antropología de la Facultad de Ciencias Naturales y Museo de la Universidad de La Plata que me otorgó una beca FOMEC para estudiar la colección Zavaleta en Chicago. Al Världskulturmuseet que también suministró apoyo para la investigación y mi estadía en Gotemburgo. A Myriam Tarragó por su generosidad para proporcionar datos inéditos. A Adriana Muñoz también agradezco sus gestiones para la obtención del fechado de Bañado-La Vaquería. A Carlos Aschero, Eduardo Ribotta, Javier Nastri, Alejandra Reynoso, Gabriel Pratolongo y Ana Vargas, por facilitarme sus trabajos inéditos. A Tim Jull del Arizona AMS Laboratory, por su especial atención con el fechado de Lampacito. A Lucas Pereyra Domingorena, por su empeño y su "ojo" para detectar vasijas perdidas entre los estantes. 


\section{REFERENCIAS CITADAS}

AMBROSETTI, J. B., 1896-99. Notas de arqueología calchaquí. Boletín del Instituto Geográfico Argentino XVII-XX: varias series.

-1906. Exploraciones arqueológicas en la Pampa Grande (Provincia de Salta). Publicaciones, Sección Antropología, 1. Universidad de Buenos Aires, Buenos Aires.

ASCHERO, C. y E. RIBOTTA, 2004 Ms. Usos del espacio, tiempo y funebria en El Remate (Los Zazos, Amaicha del Valle, Tucumán). Ponencia presentada al Taller "Investigando en Tafí: Una puesta al día”, 2004. Tafí del Valle.

BECKER-DONNER, E., 1951-52. Die Nordwestargentinischen Sammlungen des Museums für Völkerkunde (II), Archiv für Völkerkunde I/VII: 229-362.

BERENGUER, J., A. DEZA, A. ROMAN y A. LLAGOSTERA, 1986. La secuencia de Myriam Tarragó para San Pedro de Atacama: Un test por termoluminiscencia. Revista Chilena de Antropología 5: 17-54.

BOURDIEU, P., 1990. Les conditions sociales de la circulation internationales des idées. Romanitische Zeitschrift für Literaturgeschichte/Cahiers d'histoire des littératures romanes 14 (1-2): 1-10.

BREGANTE, O., 1926. Ensayo de clasificación de la cerámica del Noroeste Argentino. Facultad de Filosofía y Letras, Universidad de Buenos Aires, Buenos Aires.

BRUCH, C., 1911. Exploraciones arqueológicas en las provincias de Tucumán y Catamarca. Revista del Museo de La Plata 19.

CARRARA, M. T., G. MONTI y N. MAGNANO. 1961 Ms. Registro y dibujos de ejemplares del Museo Bravo de Cafayate.

COSTA, M. A. y A. LLAGOSTERA, 1994. Coyo-3: Momentos finales del Período Medio de San Pedro de Atacama. Estudios Atacameños 11: 73-108.

CHILTON, E., 1999. One size fits all. Typologies and alternatives for ceramic research. En Material meanings. Critical approaches to the interpretation of material culture, E. Chilton (Ed.), pp. 44-60. The University of Utah Press, Utah.

GOMBRICH, E. H., 1999 [1979]. El sentido del orden. Estudio sobre la psicología de las artes decorativas. Editorial Debate S.A., Madrid.

GONZALEZ, A. R., 1963. Cultural development in NW Argentina. En Aboriginal development in Latin America: An interpretative review, vol. 1, B. Meggers y C. Evans (Eds.), pp. 103-117. Smithsonian Miscellaneous Collection, Washington D. C.

1964. La Cultura de La Aguada del N. O. Argentino. Revista del Instituto de Antropología II-III: 205-253.
1977. Arte precolombino en la Argentina. Filmediciones Valero, Buenos Aires.

_ 1983. Notas sobre religión y culto en el Noroeste Argentino prehispánico. A propósito de unas figuras antropomorfas del Museo de Berlín. Baessler-Archiv für Volkerkunde, Neue Folge, XXXI: 212-282.

-1998. Arte precolombino. Cultura La Aguada. Arqueología y diseños. Filmediciones Valero, Buenos Aires.

GONZALEZ A. R. y M. BALDINI, 1991. Función y significado de un ceramio de la Cultura La Aguada. Ensayo de interpretación. Boletín del Museo Chileno de Arte Precolombino 5: 23-52.

GORDILLO, I., 1999. Problemas cronológicos del Período Medio en el Noroeste Argentino. Actas del XII Congreso Nacional Arqueología Argentina T 2: 362-371. La Plata.

_2004. Organización socioespacial y religión en la arqueología de Ambato: El sitio ceremonial de La Rinconada. Tesis Doctoral. Facultad de Filosofía y Letras, Universidad de Buenos Aires, Buenos Aires.

GOSSELAIN, O. P., 2000. Materializing identities: An African perspective. Journal of Archaeological Method and Theory 7 (3): 187-217.

HEREDIA, O. R., 1974. Investigaciones arqueológicas en el sector meridional de las Selvas Occidentales. Revista del Instituto de Antropología V: 73-132.

HODDER, I., 1982. Symbols in action. Cambridge University Press, Cambridge.

KORSTANJE, M. A., 1988. Aguada: Contribución al estudio de una iconografía compleja. Tesis de Licenciatura en Historia. Universidad Nacional de Tucumán, Tucumán.

KRAPOVICKAS, P., 1955. El yacimiento de Tebenquiche (Puna de Atacama). Publicaciones del Instituto de Arqueología III.

LAFONE QUEVEDO, S., 1908. Tipos de alfarería de la región diaguita-calchaquí. Revista del Museo de La Plata XV: 295-396.

LEMMONIER, P., 1992. Elements for an anthropology of technology. Anthropological Papers, Museum of Anthropology, University of Michigan, 88. Ann Arbor, Michigan.

LIBERANI, I. y J. R. HERNANDEZ, 1950 [1877]. Excursión arqueológica en los valles de Santa María, Catamarca. Instituto de Antropología, Universidad Nacional de Tucumán, San Miguel de Tucumán.

LO CELSO, M. G., 2004. El porvenir del pasado. Folleto. Museo de Antropología, Salta. 
MARCONETTO, M. B., 2005. Recursos forestales y el proceso de diferenciación social en tiempos prehispánicos en el valle de Ambato, Catamarca. Tesis Doctoral. Facultad de Ciencias Naturales y Museo, Universidad Nacional de La Plata, La Plata.

MORENO, F. P., 1890-91. Exploración arqueológica de la Provincia de Catamarca. Revista del Museo de La Plata I: $199-221$.

MÜLLER, F., 1997-98. Comentario sobre la colección de algunos objetos arqueológicos del noroeste de Argentina en el Museo Laterano (Roma, Italia). Paleoetnológica 9: 7-28.

MUÑOZ, A., 2002 Ms. Informe sobre la Colección Zavaleta en Berlín, Gotemburgo.

MUÑOZ, A. y P. STENBORG, 1999. Conclusions. En Masked histories. A re-examination of the Rodolfo Schreiter Collection from Northwestern Argentina, P. Stenborg y A. Muñoz (Eds.), Etnologiska Studier 43: 279-285.

NASTRI, J., G. PRATOLONGO, A. REYNOSOy A. M. VARGAS, 2006. Arqueología en la sierra del Cajón: Poblados, corrales y pinturas. Actas XV Congreso Nacional de Arqueología Argentina. Río Cuarto. En prensa.

NAVAMUEL, E. 1979. Desarrollo cultural precolombino en el valle de Lerma. Revista del Museo Arqueológico de Salta 2: 47-129.

NUÑEZ REGUEIRO, V., 1974. Conceptos instrumentales y marco teórico en relación al análisis del desarrollo cultural del Noroeste Argentino. Revista del Instituto de Antropología 5: 169-190.

NUÑEZ REGUEIRO, V. y M. TARTUSI, 1990. Aproximación al estudio del área pedemontana de Sudamérica. Cuadernos 12: $125-160$.

1993. Orígenes de la ocupación prehispánica del sitio StucTav 5 (El Pichao), Provincia de Tucumán. Publicaciones 2: 19-30.

2002. La Aguada y el proceso de integración regional. Estudios Atacameños 24: 9-19.

PELISSERO, N. y H. DIFRIERI, 1981. Quilmes. Editorial Gobierno de la Provincia de Tucumán, San Miguel de Tucumán.

PEREZ DE MICOU, C., 1998. Las colecciones arqueológicas y la investigación. Revista del Museo de Arqueologia e Etnologia 8: 223-233.

PEREZ GOLLAN, J. A., 1991. La Cultura de La Aguada vista desde el valle de Ambato. Publicaciones del Centro de Investigaciones de la Facultad de Filosofía y Humanidades 46: 157-173.

1998. Los sueños del jaguar. Museo Chileno de Arte Precolombino, Santiago.
2000. El jaguar en llamas (La religión en el antiguo Noroeste Argentino). En Nueva Historia Argentina: I. Los pueblos originarios y la conquista, M. Tarragó (Ed.), pp. 229-256. Editorial Sudamericana, Buenos Aires.

PEREZ GOLLAN, J. A. y O. HEREDIA, 1990. Hacia un replanteo de la Cultura de La Aguada. Cuadernos 12: 161-178.

RAFFINO, R., 1994. El N.O.A. y la integración Inka (1471-1535 DC). Rumitacana 1: 43-48.

RAFFINO, R., G. RAVIÑA, L. BALDINI y A. IACONA, 1982. La expansión septentrional de la Cultura La Aguada en el N.O. Argentino. Cuadernos 9: 179-82.

SCATTOLIN, M. C., 2000. Santa María durante el primer milenio DC. ¿Tierra baldía? Årstryck 1995-1998: 63-83.

-2004 Ms. Santa María antes del año mil: Fechas y materiales para una secuencia cultural. Ponencia presentada en el Taller Internacional de Arqueología del Noroeste Argentino y Andes Centro-Sur. Buenos Aires, 2004.

SCATTOLIN, M. C., M. F. BUGLIANI, L. PEREYRA DOMINGORENA y L. CORTES, 2005. La señora de los anillos, entre otras tumbas presantamarianas de Yocavil. Intersecciones en Antropología 6: 29-41.

SEMPE, M. C. y M. A. ALBECK, 1981. La cerámica de interior negro bruñido en el N.O. Argentino. Su ubicación espaciotemporal y cultural. Revista Española de Antropología Americana 11: 161-181.

SERRANO, A., 1966. Manual de cerámica indígena. Editorial Assandri, Córdoba.

SHENNAN, S., 1989. Introduction. En Archaeological approaches to cultural identity, vol. 10, S. Shennan (Ed.), pp. 1-32. One World Archaeology, Unwin and Hyman, Londres.

STENBORG, P. y A. MUÑOZ (Eds.), 1999. Masked histories. A re-examination of the Rodolfo Schreiter Collection from Northwestern Argentina. Etnologiska Studier 43.

TARRAGO, M., 1989. Contribución al conocimiento arqueológico de las poblaciones de los oasis de San Pedro de Atacama en relación con los otros pueblos puneños, en especial el sector septentrional del valle Calchaquí. Tesis para optar al Título de Doctor en Historia, Especialidad Antropología. Universidad Nacional de Rosario, Facultad de Humanidades y Artes, Rosario.

_ 1999. Palabras finales. En Masked histories. A re-examination of the Rodolfo Schreiter Collection from Northwestern Argentina, P. Stenborg y A. Muñoz (Eds.), Etnologiska Studier, 43: 287-290.

TARRAGO, M. y M. C. SCATTOLIN, 1999. La problemática del Período Formativo en el valle de Santa María. Actas del XII Congreso Nacional de Arqueología Argentina T 1: 142-153. La Plata.

TARRAGO, M., L. GONZALEZ y J. NASTRI, 1997. Las interacciones prehispánicas a través del estilo: El caso 
de la iconografía santamariana. Estudios Atacameños 14: $223-242$.

TARTUSI, M. y V. NUÑEZ REGUEIRO, 2001. La presencia de Aguada en la Provincia de Tucumán, Argentina. Ponencia presentada a la IV Mesa Redonda "La cultura de La Aguada y su dispersión", San Pedro de Atacama, 2000. http:www.geocities.com/aguadamesaredonda. Visitado: 2003.

VON TSCHUDI, J. J., 1866-69. Reisen durch Südamerika. Band 1/5, Leipzig.

WASHBURN, D., 1989. The property of symmetry and the concept of ethnic style. En Archaeological approaches to cultural identity, vol. 10, S. Shennan (Ed.), pp. 157-173. One World Archaeology, Unwin and Hyman, Londres.

WILLIAMS, V., 2003. Nuevos datos sobre la prehistoria local en la quebrada de Tolombón. Provincia de Salta. Argentina. En Local, regional, global: Prehistoria, protohistoria e historia en los Valles Calchaquíes, P. Cornell y P. Stenborg (Eds.), Anales Nueva Epoca 6: 165-210.

WOLF, K. L. y D. KUHN, 1977 [1952]. Forma y simetría. Eudeba, Buenos Aires.

ZAVALETA, M. B., 1906. Catálogo de la Colección Calchaquí de arqueología y antropología. Imprenta Petenello Hnos., Buenos Aires. 